\title{
Power Prediction-Based Model Predictive Control for Energy Management in Land and Air Vehicle with Turboshaft Engine
}

\author{
Zhengchao Wei $\mathbb{D}^{1},{ }^{1}$ Yue Ma $\mathbb{C D}^{1,2}$ Changle Xiang, ${ }^{1}$ and Dabo Liu ${ }^{2}$ \\ ${ }^{1}$ Beijing Institute of Technology, Beijing 100081, China \\ ${ }^{2}$ Beijing Institute of Technology Chongqing Innovation Center, Chongqing 401120, China \\ Correspondence should be addressed to Yue Ma; yuema@bit.edu.cn
}

Received 10 May 2021; Accepted 18 August 2021; Published 27 August 2021

Academic Editor: Weixiang Zhou

Copyright (C) 2021 Zhengchao Wei et al. This is an open access article distributed under the Creative Commons Attribution License, which permits unrestricted use, distribution, and reproduction in any medium, provided the original work is properly cited.

\begin{abstract}
In recent years, the green aviation technology draws more attention, and more hybrid power units have been applied to the aerial vehicles. To achieve the high performance and long lifetime of components during varied working conditions, the effective regulation of the energy management is necessary for the vehicles with hybrid power unit (HPU). In this paper, power predictionbased model predictive control ( $\mathrm{P}^{2} \mathrm{MPC}$ ) for energy management strategy (EMS) is proposed for the vehicle equipped with HPU based on turboshaft engine in order to maintain proper battery's state of charge (SOC) and decrease turboshaft engine's exhaust gas temperature (EGT). First, a modeling approach based on data-driven method is adopted to obtain the mathematical model of turboshaft engine considering time delay and inertial of states. An integrated power predictor consisting of the classification of input status and the subpredictors are developed based on the deep learning method to improve the accuracy of the prediction model of the model predictive control (MPC). Subsequently, an EMS based on MPC using the proposed power predictor is introduced to regulate the SOC of battery and the EGT of turboshaft engine. The comparison with experimental results shows the high accuracy of mathematical model of turboshaft engine. The simulation results show the effectiveness of the proposed EMS for the vehicle, and the effects of different weight coefficients of objective function on the proposed EMS are discussed.
\end{abstract}

\section{Introduction}

With the rapid urbanization and the continuous population growth, more and more vehicles are used to satisfy the requirements of transportation such as freight transportation and public transportation. However, the more vehicles bring the more traffic pressure to the transportation. Conventional vehicles only can run on the land, which cannot make full use of the public space. Land and air vehicle is a promising solution orienting the future transportation, which is capable of running on the land by wheels like conventional vehicle and flying in the air by rotary-wing or fixed-wing. Consequently, the integration of multiple functions of the land and air vehicle can contribute to relieving the traffic pressure and improving traffic efficiency.

However, more driving power is required by the land and air vehicle to meet the demands from different usage situations compared to the conventional vehicles. Generally, it is believed that the greenhouse gas emission, global warming, and air pollution are the main environmental problems as a result of the ongoing use of fossil fuel resources, and more driving power of vehicles means the more use of fossil fuel resources. If the full driving power of the land and air vehicle is still provided by the conventional combustion engine which uses fossil fuel without any improvement, it makes no contribution to energy conservation and pollution reduction. According to the research reports, the aviation sector is responsible for $2 \%$ of the total fuel consumption in the transportation sector. If this trend of using fossil fuel resources in aviation continues without any alternative methods, this number is expected to increase up to $11 \%$ within the next two decades [1]. To minimize the negative impacts such as air pollution and the greenhouse effect on environment, the green aviation technology which 
reduces the fossil fuel consumption and emissions in transportation industry is a current main concern. Therefore, it is crucial to develop the green aviation technology on the land and air vehicles, and finding alternatives to fossil fuels in aviation is more important now than ever. To achieve low emissions, low fuel consumption, and high efficiency, it is necessary to improve the vehicle power systems greatly.

Hybrid and pure electric driving solutions have been applied in the automotive industry for many years and great success has been gained in the ground vehicle, recently these environmentally friendly solutions are being exploited for unmanned aerial vehicles and general aviation aircraft, and some research results about electric and hybrid power unit power demand estimation, reduction of required power, and battery sizes have been obtained [2-8]. Moreover, before the energy density of storage system can be increased greatly, the hybrid power unit (HPU) is the most excellent solution and it has more advantages in the endurance mileage because of the combined utilization of engine and energy storage system compared with pure electric power systems. Therefore, the applications of HPU on the aerial vehicle are paid more attention. The configuration and architecture of HPU can be mainly divided into two types [5]: series HPU and parallel HPU. The series HPU decouples the engine from the power demand, which provides an opportunity to allow the engine continuously operating in high-efficient or less-emission area. Therefore, the series HPU has a promising development on aerial vehicles.

Because of the success of hybrid-electric solution on conventional vehicles, piston engine is usually adopted in HPUs. In fact, turboshaft engine has higher power to weight ratio in comparison to piston engine, especially when it concerns high power requirement, and these advantages make the turboshaft engine have preferable performance in HPU [9]. There are lots of obvious differences including but not limited to structure and aerospace features between the turboshaft engine and the piston engine, therefore the investigation on HPU with turboshaft engine is worth exploring for better performance of aerial vehicles [10]. To analyze the impacts of turboshaft engine on the HPU, an accurate engine model which can reflect the characteristics is necessary. Some methods have been developed to realize the modeling of turboshaft engine [11-15]. The modeling by mechanism based on aerothermodynamics is a common method, which is adopted widely to obtain the model of gas turbine. The modeling by mechanism can offer the internal parameters of engine such as pressure ratio of compressor and inlet temperature of turbine. However, it heavily relies on the characteristics of components and the knowledge of aerothermodynamics of the researcher. Besides, neutral network modeling method is also applied for modeling of engine. However, a lot of experimental data and time are necessary to train the neutral network model, and the convergent speed and accuracy of model are not guaranteed. Compared with the modeling methods mentioned above, data-driven modeling method uses the experimental data of objects to acquire the steady-state and dynamics characteristics, and fast calculation speed and high accuracy of model by data-driven method are the advantages when the internal parameters of objects are not concerned. Therefore, the data-driven method is effective for the modeling of the turboshaft engine. Considering the application of turboshaft engine, the dynamics characteristics of turboshaft engine model are focused in this paper. In reference [16], related gain coefficients among rotate speed, fuel, and EGT are used to model the two-spool turboshaft engine based on the experimental data, and the selections of gain coefficients in simulation rely on the rotate speed. In references $[14,17]$, the dynamics model of one-spool turboshaft engine is built for the startup process, but the dynamics characteristics in loading process at rated rotate speed are not discussed. In fact, the turboshaft engine with one-spool in HPU is used as the main energy source to output power, and the dynamics characteristics of the engine can have an impact on the performance of HPU. Therefore, the dynamics characteristics of the engine in loading process at rated rotate speed are worth studying.

The allocation of energy among energy sources has profound effect on improving efficiency of the components in the aerial vehicles. The appropriate energy management strategies can greatly develop the potential of HPU. Generally, the EMS of HPU can be divided into two types, namely, rule-based and optimization-based [18-26]. The rule-based control depends on the past and current system states to determine the modes of operation. Therefore, it is easily implemented as the real-time control strategy. The rule-based energy management strategies (RBEMS) mainly consist of the deterministic rule-based control and fuzzy logic control. The deterministic rule-based control employs the classic set theory and elements to define different modes of operation, and the transitions between the different modes are determined by the designed rules. Different from the deterministic rule-based control, the fuzzy logic control deals with reasoning using an approximate way rather than the precise way. In general, the rule-based control strategies are developed based on the practical experience of researchers, and vehicles using the specific RBEMS can obtain the good performance when the vehicle runs on the specific driving condition. However, it is difficult that the specific RBEMS meets the requirements from different and varying working conditions. On the other hand, the optimizationbased EMS regulates the control variables based on calculation by minimizing a predefined cost function within feasible constraints. The optimization-based approaches can be divided into global optimization and real-time optimization. Dynamic programming (DP) is frequently applied in global optimization control strategy and the vehicle using DP can obtain the best performance of targets while dealing with the hybrid energy management problems. However, the overall working conditions of the future are required to be known in advance for global optimization control, which is extremely difficult in real applications. Among real-time optimization methods, model predictive control (MPC) is a promising method [27-29]. According to the MPC theory, by predicting the required parameters in the finite time horizon of the future, the control variables can be gained by minimizing the multiobjective optimization function. Compared to DP, the multiobjective optimization function 
of MPC method can be solved online because of the latest prediction parameters during different working conditions, and the good control effect of the MPC method can be obtained if the prediction parameters are accurate enough.

For hybrid power system unit, the power demand is the main key factor for accurate prediction model in MPC [30-32]. The conventional MPC method is also called as the frozen-time MPC, and the power demand is assumed to be constant equal to that in current time step over the prediction horizon for the prediction model simplification. However, the problem is that this assumption ignores possible changes to the power demands during the prediction horizon, and it may lead to inaccurate prediction model, which can bring poor control performance of MPC method, especially in sharp driving condition. The short sampling time interval in the prediction horizon is the potential method to increase the reliability of prediction model for conventional MPC. However, during actual aerial vehicle operation with HPU, the short sampling time generally means high sampling frequency of sensors and it can lead to high cost on sensors and large electrical energy consumption. Therefore, how to obtain the accurate change information of future power demand in prediction horizon is necessary to improve the MPC-based EMS for vehicle with HPU. The power demands closely relate to the velocity of the vehicles. Hence, the velocity prediction method is focused in this paper. There are several speed prediction methods [21-23, 31] including exponential function prediction, Markov chain prediction, and deep learning model prediction. In reference [21], a comparative study shows that an EMS with an ANN-based velocity predictor can achieve better performance in minimizing fuel consumption compared with Markov chain models. In reference [32], combined with the velocity predicted by a radius basis function neural network, an EMS based on the MPC can improve fuel economy better. Therefore, the deep learning prediction method is a potential candidate due to its high accuracy. In fact, different driver behaviours and the trend of vehicle states can have an impact on different future speed distributions. However, conventional velocity prediction models usually ignore the characteristics of inputs mentioned above. The internal parameters of conventional velocity prediction model are fixed and cannot change based on the input driving states $[22,31,32]$, which cannot guarantee prediction accuracy. Hence, an integrated velocity prediction model that can change the internal parameters to adapt to various input driving states should be further studied.

Therefore, in this paper, an energy management strategy based on power prediction MPC for vehicles with turboshaft engine is proposed. The following are the main contributions of this paper:

(1) For simplifying model and guaranteeing the accuracy of model, based on experimental data, a modeling approach based on data-driven method is adopted to build mathematical models of turboshaft engine during startup process and loading process considering time delay and inertial of states.
(2) An integrated power predictor developed based on the deep learning method is proposed to forecast the future power demands. The proposed integrated power predictor consists of various subpredictors, and different predictive subpredictors are used for prediction based on the classification of input states from historical velocity and acceleration/brake pedal signal.

(3) To achieve coordinated deviation of SOC of battery and EGT of turboshaft engine, a power predictionbased MPC framework for EMS is designed with the proposed integrated power predictor, and the effect of different weight coefficients of objective function in the proposed EMS is discussed to determine the proper weights combination for desirable control performance.

This paper is organized as follows. In Section 2, the distributed structure of a land and air vehicle is introduced and the models of components such as turboshaft engine are established for EMS research. In Section 3, energy management problem is introduced; the power prediction method based on deep learning for MPC is proposed. In Section 4 , the accuracy of the turboshaft engine model based on data-driven method is shown compared with experimental data. The performance comparison between conventional MPC and deep learning prediction-based MPC is performed. Besides, the effects of different weight coefficients in multiobjective function of the proposed EMS on control performance are discussed. The rule-based EMS and the proposed EMS are compared and discussed. Some conclusions are drawn in Section 5.

\section{Configuration and Modeling}

2.1. Configuration of Vehicle. The distributed structure of land and air vehicle with HPU is designed and produced by Vehicle Research Center in Beijing Institute of Technology. The topological structure is shown in Figure 1. There are four wheels and distributed driving motors mounted on the chassis to propel the vehicle on land, and eight main propellers with motors provide the lift for air mode. Electric power for moving on the land and flying in the air is from the HPU. The HPU adopts the series hybrid-electric configuration to simplify the vehicle structure, thus there is no mechanical connection between the engine and the drive motor; the configuration of HPU is shown in Figure 2. The turboshaft engine and the generator are connected mechanically as the main energy source of HPU, and the power battery is used as an auxiliary energy source for voltage stabilization and power compensation. The electric power from HPU is transmitted to the driving motors for meeting the power requirement. The application of CAN bus in the vehicle realizes communication among controllers of systems and supports the controllers monitored by the master vehicle control unit, which contributes to the simplification and lightweight design for the vehicle. 


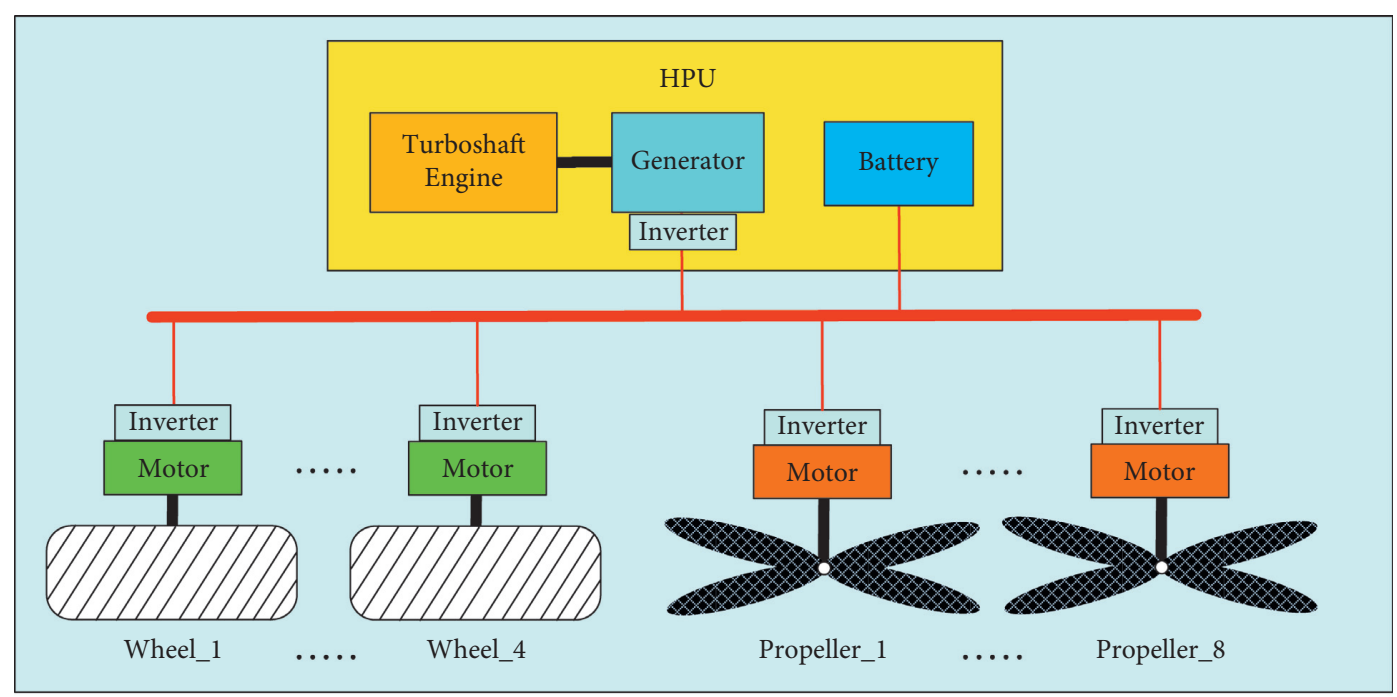

- Mechanical Connection
Electrical Connection

FIgURE 1: Description of the land and air vehicle with HPU.

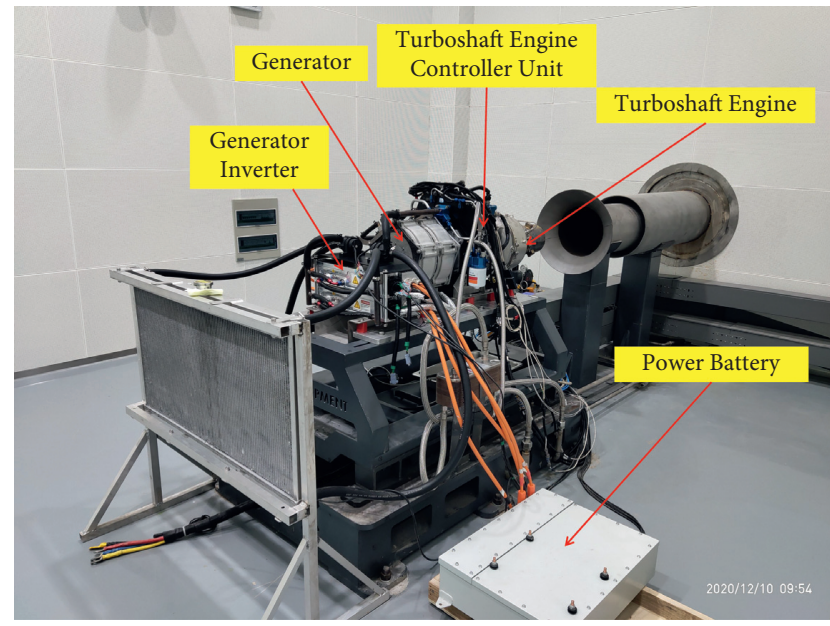

Figure 2: Configuration of HPU.

2.2. Modeling of Vehicle. Because of the feature of application environments, the vehicle usually runs in land mode during most of the working time. To achieve the high efficiency and long life of components, the research about EMS of the vehicle with HPU under the complex road working condition is important, and the models of components of vehicle such as turboshaft engine and dynamic battery should be established firstly. The rotor wings and the motors which drive rotor wings are not used in land mode, therefore these components are treated as mass loads in the model of vehicle.

\subsubsection{Modeling of Turboshaft Engine Based on Data-Driven} Method. The turboshaft engine is mainly composed of the inlet, compressor, combustion chamber, turbine, gearbox, and other subsystems. The airflow from inlet is compressed by compressor, and the fuel is injected into the airflow to produce the mixture of fuel and air. The mixture of fuel and air is ignited in combustion chamber. The fuel gas from combustion offers the power for turbine to rotate. The turbine can drive the compressor and provide the power to balance loads for stable rotate speed.

Generally, there are two mainly modeling methods for turboshaft engine: the analytical modeling method and the experimental modeling method. The analytical modeling method for turboshaft engine needs accurate components performance data, such as compressor and turbine performance data, and the researchers who use analytical modeling method are required to know lots of knowledge on thermodynamics. However, the turboshaft engine model by the analytical modeling method usually costs lots of time to calculate the parameter value in the simulation test because of a lot of iterations, which is not helpful for the simulation process.

In fact, modeling method by the data-driven method focuses on the input-output parameters based on the experimental data, and it is easier to model the engine for researchers without detailed information about turboshaft engine construction. In this paper, to establish the turboshaft engine model reflecting dynamic response characteristics, a modeling method for dynamics model of turboshaft engine combined with dynamic coefficient based on experimental results data is adopted. The engine starting experiment and load experiment have been conducted on the turboshaft engine to collect the performance data, and the experimental results including speed, fuel flow, torque, and EGT are shown as Figures 3 and 4.

In the engine starting experiment, the engine rotation speed increases from $0 \mathrm{r} / \mathrm{min}$ to $62000 \mathrm{r} / \mathrm{min}$ gradually and the fuel flow also increases from $0 \mathrm{~L} / \mathrm{h}$ to $47.3 \mathrm{~L} / \mathrm{h}$. In the engine load experiment, the output power increases from $0 \mathrm{~kW}$ to $115 \mathrm{~kW}$ gradually, and similarly the fuel flow 


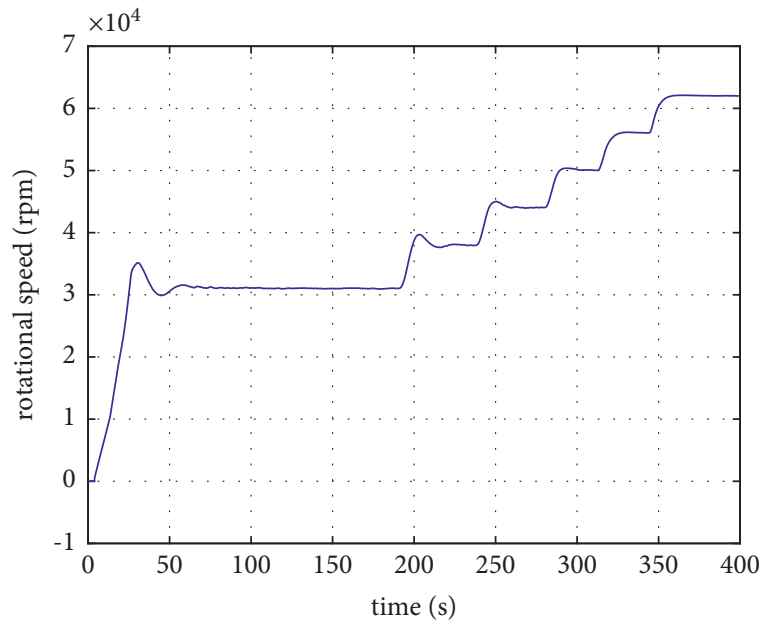

(a)

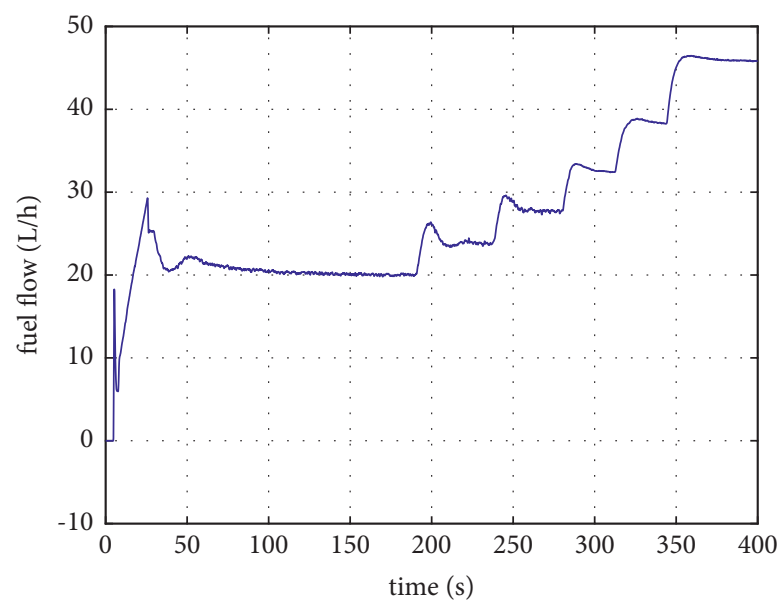

(b)

Figure 3: Engine starting experimental results. (a) Spool rotate speed. (b) Fuel flow.

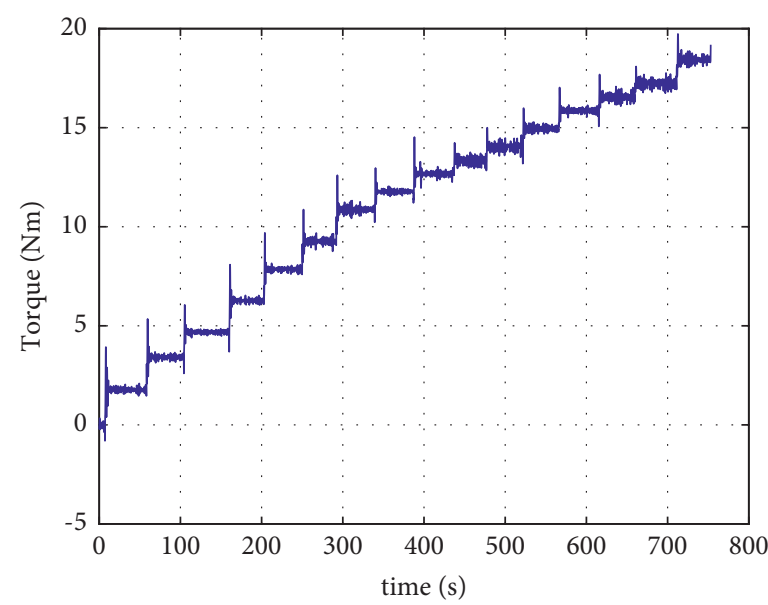

(a)

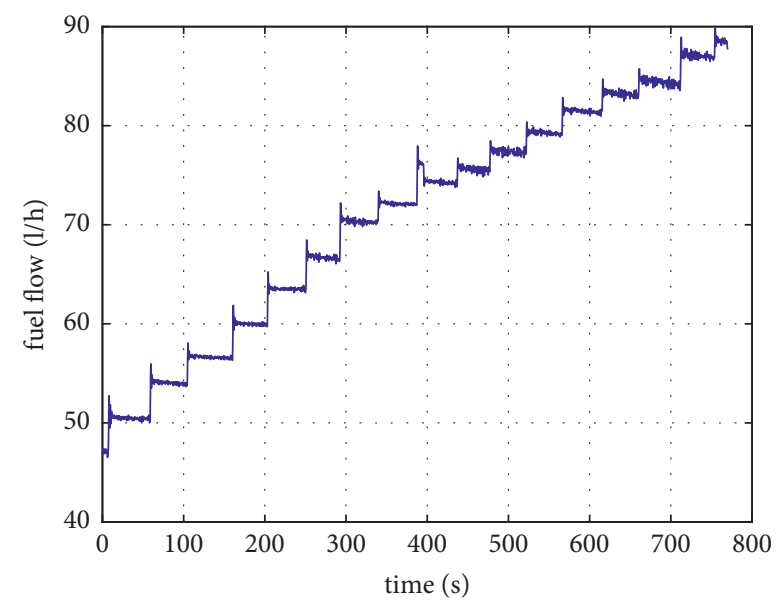

(b)

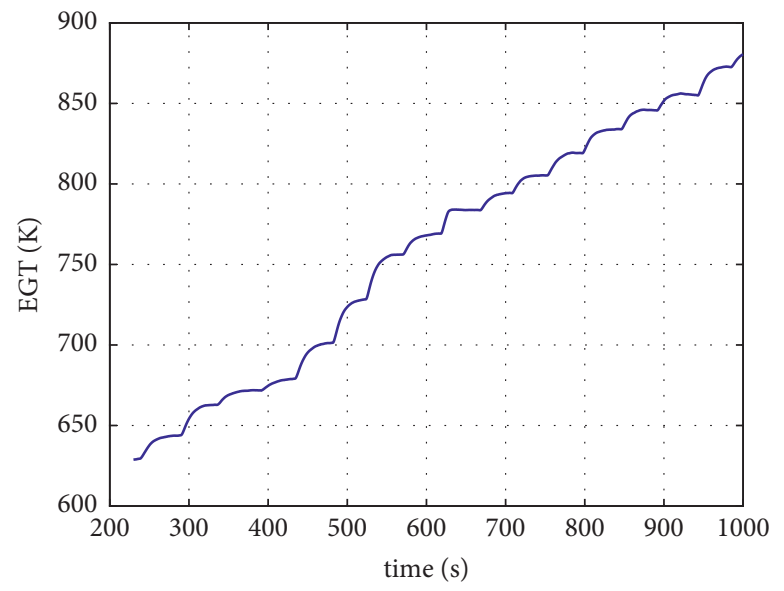

(c)

FIgURE 4: Engine load experimental results. (a) Torque. (b) Fuel flow. (c) EGT. 
increases from $47.3 \mathrm{~L} / \mathrm{h}$ to $89.0 \mathrm{~L} / \mathrm{h}$. The rotation speed stabilizes at around $62000 \mathrm{r} / \mathrm{min}$ during loading experiment because of the engine controller. When the power loads vary, the engine can adjust the output power for balancing the power loads to achieve the purpose of stable speed.

According to turboshaft engine theory, at certain atmospheric temperature and pressure, the output performances of turboshaft engine, such as rotation speed and torque, are approximately determined by the fuel flow when the vane angles of compressor and turbine do not change. As shown in Figures 3 and 4, when the engine rotation speed is stable at around $31000 \mathrm{r} / \mathrm{min}$ in the engine starting experiment, the fuel flow also stabilizes at around $20.0 \mathrm{~L} / \mathrm{h}$. Similarly, when the output torque is stable at around $7.85 \mathrm{Nm}$ in engine loading experiment, the fuel flow also stabilizes at around $63.5 \mathrm{~L} / \mathrm{h}$. The steady-state data relationship is shown in Figure 5.

Based on the data in Figure 5, the steady-state fuel flow is described by

$$
\begin{aligned}
& W_{\text {fs-start }}=f_{\text {start }}\left(n_{e}\right), \\
& W_{\text {fs-load }}=f_{\text {load }}\left(T_{e}\right),
\end{aligned}
$$

where $n_{e}$ is the engine spool rotate speed in engine starting process and $T_{e}$ is the engine output torque in engine loading process, which is different from the work in reference [16] where the $n_{e}$ is used rather than $T_{e}$ in engine loading process. The reason for choosing the $T_{e}$ is that the rotate speed of turboshaft engine in this paper is constant in normal working state. $W_{\mathrm{fs}-\mathrm{start}}$ and $W_{\mathrm{fs}-\text { load }}$ are the steadystate fuel flows calculated by interpolation algorithm. When the actual fuel flow changes from the "steady-state point," the actual output performances such as speed or torque also change from the "steady-state point" into dynamic state, which means the change of fuel flow has an impact on dynamic state of engine. The difference between actual fuel flow and steady-state fuel flow usually is known as the actual residual fuel flow. The actual residual fuel flow can be expressed as

$$
\Delta W_{f}=W_{f}-W_{f_{s-x}}
$$

where $W_{f}$ is the actual fuel flow and $W_{f-x}$ indicates the steady-state fuel flow $W_{\mathrm{fs}-\text { start }}$ in the engine starting process or $W_{\text {fs-load }}$ in the engine loading process, which can be calculated by equation (1); the corresponding change of output torque of turboshaft engine can be expressed as

$$
\Delta T_{e}=T_{e}-T_{e s-x}
$$

where $T_{e}$ is the actual output torque and $T_{\text {es-x }}$ is the steadystate output torque $\mathrm{T}_{\text {es-start }}$ in the engine starting process or $T_{\text {es-load }}$ in the engine loading process, which can be obtained from experimental results in Figures 3 and 4 . The dynamics coefficient $\mathrm{K}_{\mathrm{t}-\mathrm{x}}$ can be described respectively as follows:

$$
\begin{gathered}
K_{\mathrm{t}-\text { start }}=\frac{\Delta T_{\mathrm{e}-\text { start }}}{\Delta W_{\mathrm{f}-\text { start }}}=\frac{T_{e}-T_{\mathrm{es}-\text { start }}}{W_{f}-W_{\mathrm{fs}-\text { start }}}, \\
K_{\mathrm{t}-\text { load }}=\frac{\Delta T_{\mathrm{e}-\text { load }}}{\Delta W_{\mathrm{f}-\text { load }}}=\frac{T_{e}-T_{\text {es-load }}}{W_{f}-W_{\text {fs-load }}},
\end{gathered}
$$

where $K_{\mathrm{t} \text {-start }}$ is determined by engine rotate speed in engine starting process and $K_{\mathrm{t} \text {-load }}$ is determined by engine output torque in engine loading process. In addition, the time delay of output torque should be concerned because of the combustion process and power delivery. Assuming time delay parameter is $\tau$, based on the experiment result data, the $\tau$ is fitted to polynomial by least squares method, as shown in Figure 6.

Therefore, the rotor dynamics of output shaft of turboshaft engine are denoted as

$$
\begin{aligned}
& T_{e}=T_{e 0}+\int_{0}^{t} \Delta W_{f}(t-\tau) K_{t-x}, \\
& n_{e}=n_{e 0}+\int_{0}^{t} \frac{1}{J}\left(T_{e}-T_{\text {load }}\right),
\end{aligned}
$$

where $T_{e 0}$ is the initial torque, $\mathrm{K}_{t-x}$ is the dynamics coefficient such as $K_{\mathrm{t} \text {-start }}$ or $K_{\mathrm{t} \text {-load }}, \Delta W$ is the actual residual fuel flow, $T_{\text {load }}$ is the actual load torque, $J$ is the rotor inertia of output shaft, and $\tau$ is the time delay parameter. Similarly, the steady-state relationship between EGT and fuel flow is shown in Figure 7.

The dynamics model of EGT is treated as the first order inertia plant with time delay; the transfer function is described by

$$
\frac{\operatorname{EGT}_{\text {engine }}(s)}{P_{\text {engine }}(s)}=\frac{K}{T_{\text {egt }} s+1} e^{\tau_{\text {egt }} s},
$$

where $K$ is the steady-state gain coefficient, $\tau_{\text {egt }}$ is the time delay parameter, and $T_{\text {egt }}$ is the time constant, which are fitted to polynomial by least squares method, as shown in Figure 8 .

2.2.2. Modeling of Electric Generator and Motor. The dynamics models of generator and drive motor are described as the first order inertia plants, which are expressed as

$$
\begin{gathered}
\frac{T q_{g}(s)}{T q_{\mathrm{g}-\mathrm{cmd}}(s)}=\frac{1}{T_{g} s+1}, \\
\frac{T q_{m}(s)}{T q_{\mathrm{m}-\mathrm{cmd}}(s)}=\frac{1}{T_{m} s+1},
\end{gathered}
$$

where $T q_{g}$ and $T q_{m}$ are the output torques of the generator and drive motor, respectively, $T q_{\mathrm{g}-\mathrm{cmd}}$ and $T q_{\mathrm{m} \text {-cmd }}$ are the reference torques of the generator and drive motor, respectively, and $\mathrm{Tg}$ and $\mathrm{Tm}$ are the time constants. 


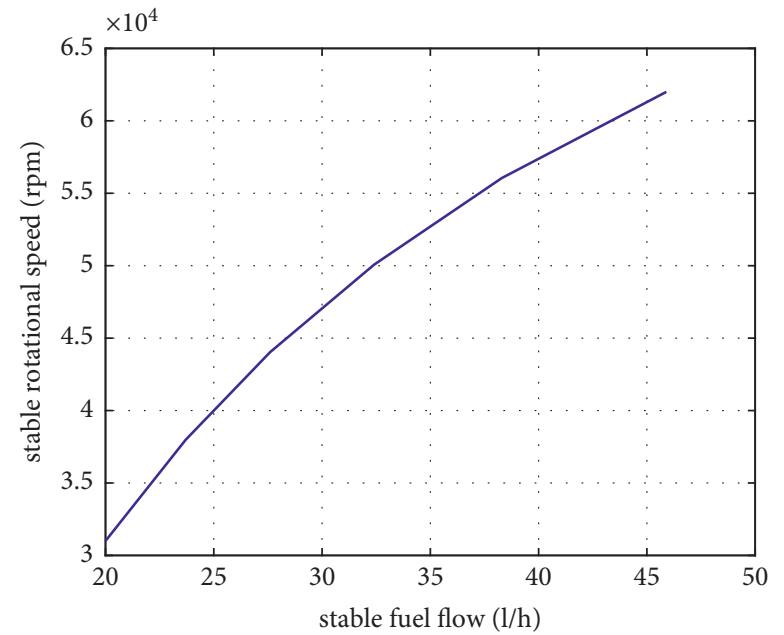

(a)

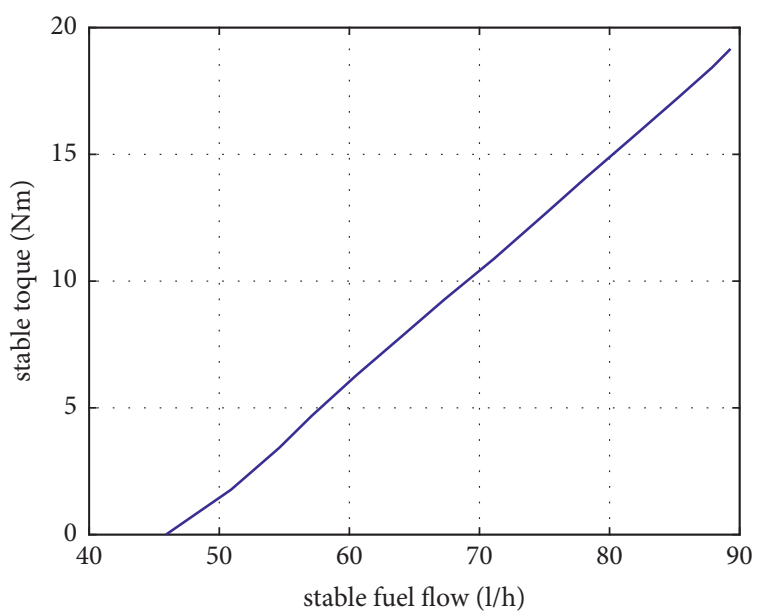

(b)

Figure 5: Steady-state data relationship. (a) Stable fuel flow vs stable speed. (b) Stable fuel flow vs stable torque.

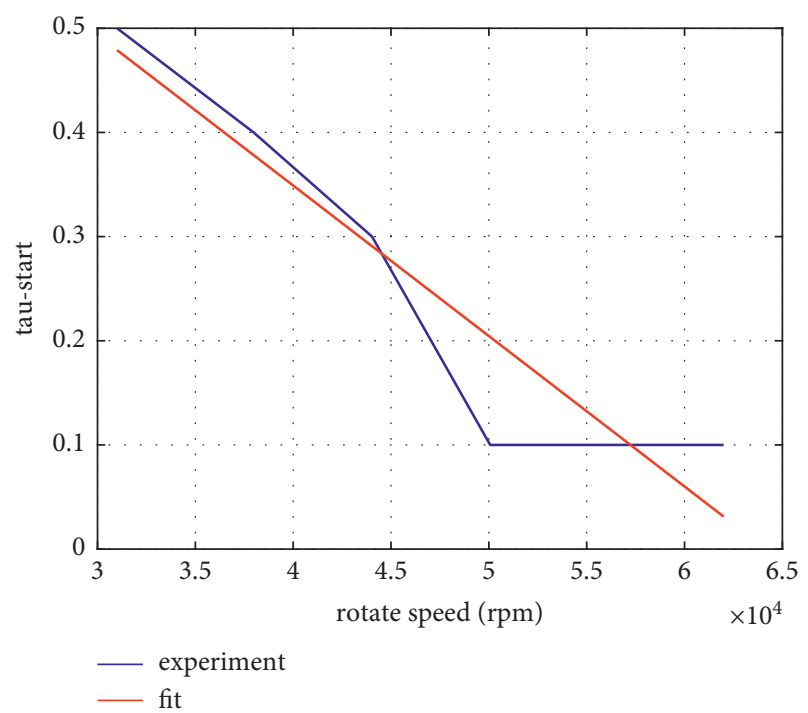

Figure 6: Comparison between fitted time delay parameter and experimental data.

2.2.3. Modeling of Power Battery. The internal resistance model is applied to simulate the characteristics of the battery; the equations are as follows:

$$
\left\{\begin{array}{l}
U_{\text {out }}=U_{\mathrm{ocv}}-\mathrm{IR}, \\
I=\frac{\left(P_{e-g}+P_{\text {motor }}\right)}{U}, \\
\mathrm{SOC}=\frac{\left(Q_{\text {int }}-\int I(t) \mathrm{d} t\right)}{\mathrm{Q}}, \\
P_{e-g}=\frac{T q_{g} n_{e}}{9549},
\end{array}\right.
$$

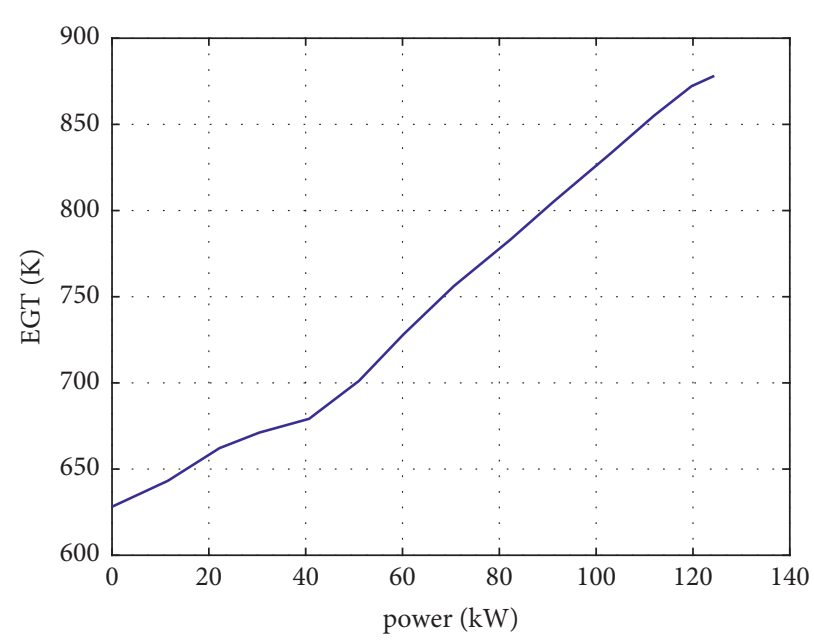

FIgURE 7: Stable power vs stable EGT.

where $U_{\text {ocv }}$ is the open-circuit voltage of the battery, $U_{\text {out }}$ is the output voltage, $I$ is the battery current, $R$ is the internal resistance of the battery, $P_{\text {motor }}$ is the power of the motor and $P_{e-g}$ is the power of engine-generator set, and SOC represents the state of charge of battery.

2.2.4. Modeling of Driving Wheel Dynamics. The vehicle obtains the driving force from the land by the wheels. The driving wheel dynamics equation is

$$
\dot{w}=\frac{T q_{\text {motor }} i-T q_{f}}{J_{\text {wheel }}},
$$

where $T q_{\text {motor }}$ is the output torque of drive motor, $J_{\text {wheel }}$ is the equivalent rotor inertia of the driving wheel, $i$ is the drive motor to drive wheel ratio, and $T q_{f}$ is the driving resistance torque. 


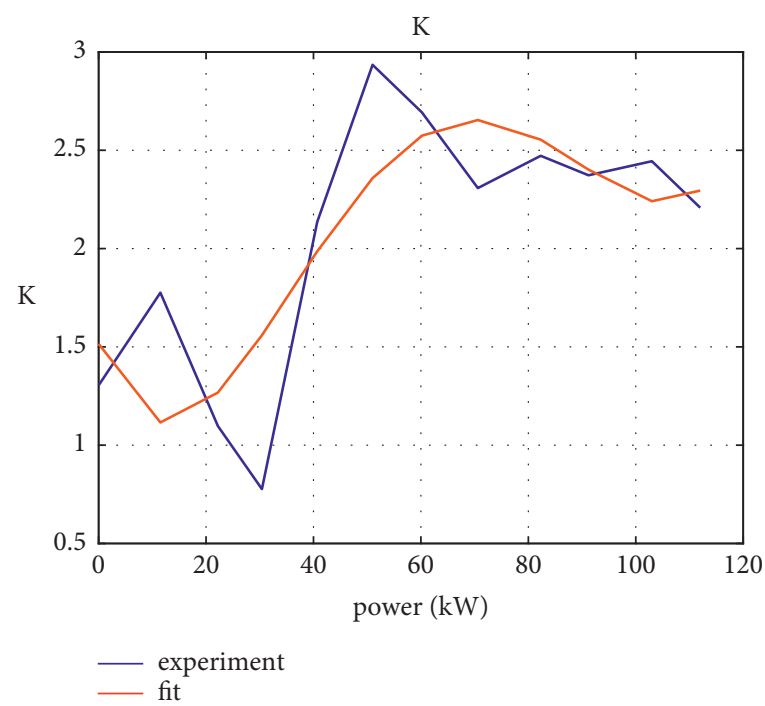

(a)

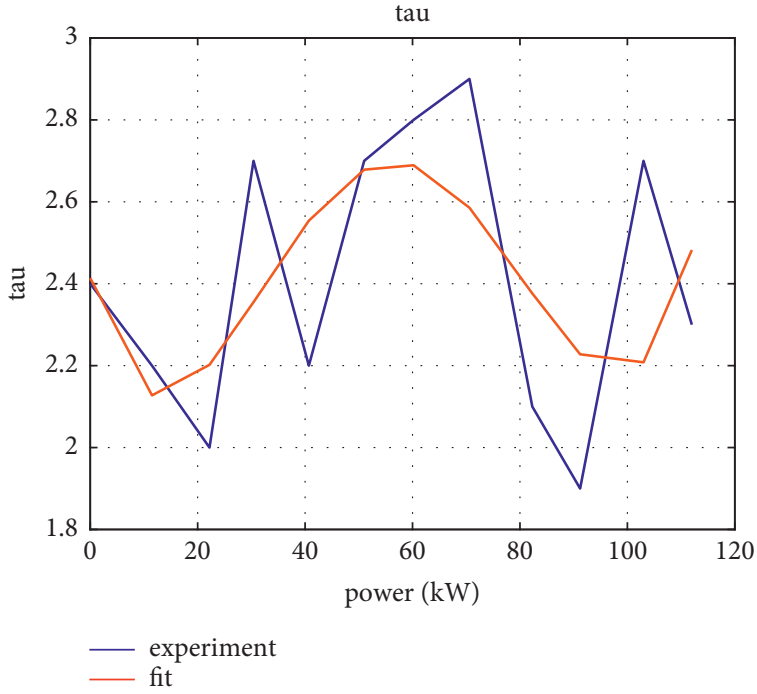

(b)

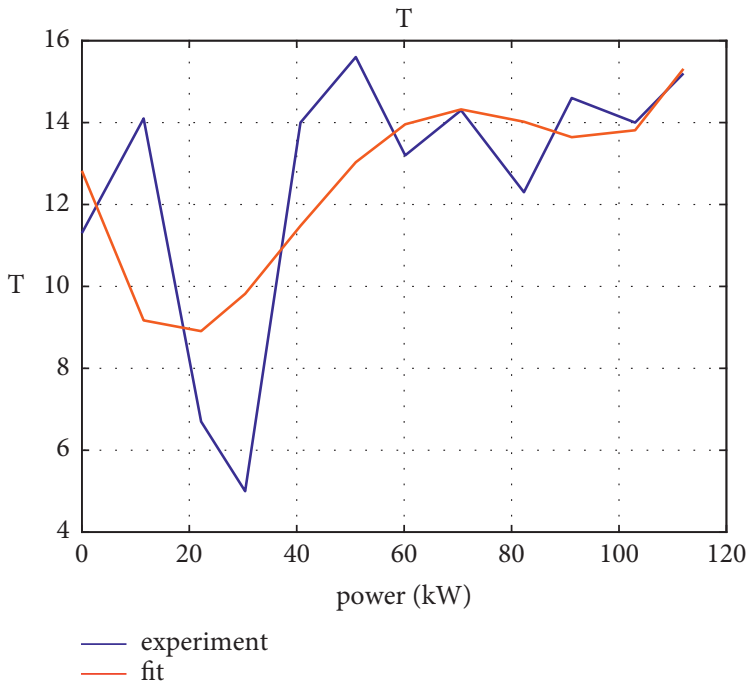

(c)

Figure 8: Comparison between fitted parameter and experimental data. (a) Steady-state gain coefficient $K$. (b) Time delay parameter $\tau_{\text {egt }}$. (c) Time constant $T_{\text {egt }}$.

\section{Power Prediction-Based MPC ( $\mathbf{P}^{2}$ MPC) for EMS}

3.1. Problem Statement. According to vehicle dynamics, the power provided by HPU should be in balance with the environment resistance power and acceleration resistance power. The power demand $P_{\mathrm{de}}$ of the vehicle can be expressed as

$$
P_{\text {de }}=P_{\text {resist_env }}+P_{\text {acc }} \text {, }
$$

where $P_{\text {resist_env }}$ is the environment resistance power and $P_{\text {acc }}$ is the acceleration resistance power. In order to meet the power demand, the total output power of HPU should be equal to power demand $P_{\mathrm{de}}$. The equation is described by

$$
P_{\mathrm{de}}=P_{e-g}+P_{\text {batt }} \text {, }
$$

where $P_{\text {batt }}$ is the power of battery. To achieve the low fuel consumption and good performance, how to effectively distribute the power between $P_{e-\mathrm{g}}$ and $P_{\text {batt }}$ is focused. Compared to other energy management strategies, MPC is a model-based closed-loop optimal control method whose control action is obtained by solving the open-loop optimal control problem for a prediction horizon. The controlled state variables are monitored and delivered to the MPC objective function for the optimal control sequence calculation based on the predictive model, and only the first element of the control sequence is applied. The other elements are ignored considering the error of predictive model.

According to the MPC theory, the accuracy of the predictive model plays a vital role in improving the control performance. For the vehicle with HPU, the power demand from environment is the key factor in the predictive model 
$[22,33]$. In this paper, a power prediction-based MPC $\left(\mathrm{P}^{2} \mathrm{MPC}\right)$ method is introduced into the EMS for vehicles with HPU. The operation process of the proposed EMS is displayed in Figure 9.

As shown in Figure 9, $\mathrm{P}^{2} \mathrm{MPC}$ method adopts the power predictor with integrated deep neural network models to obtain the future change of power demands. Subsequently, the predictive power demands and the current vehicle states including the SOC and EGT of turboshaft engine are delivered into MPC controller to achieve the optimal control command. Different from the conventional MPC which assumes the power demands to be constant over the prediction horizon, the accurate power demands from the power predictor can improve the accuracy of the prediction model in MPC controller, which can contribute to the high performance of the EMS on the vehicle with HPU.

3.2. Deep Learning-Based Power Prediction. According to the theory of MPC, the accurate future change of state variables of controlled objects in a prediction horizon should be estimated in order to achieve the accurate prediction model. The future change of power demand $\mathrm{P}_{\mathrm{de}}$ plays a vital role on MPC and is usually determined by vehicle velocity. There are several popular vehicle velocity prediction methods: exponential function prediction, Markov chain prediction, deep learning model, and so on. In this paper, the deep neural networks learning is adopted to predict velocity due to its high accuracy. The predictive power demands in upcoming period of time can be obtained by vehicle dynamics calculation.

A deep neural network determines the relationship between its inputs and outputs through training method. Its essence is to learn and form the rules between input and output data. A deep neural network model uses the error value between network output and expected output to train the network structure; the parameters in the neural network can be adjusted to make the mean square error reach the minimum possible value, which makes the network output reach the expected value as closely as possible. Finally, the training process for deep neural network is over and the parameters such as weight and bias in deep neural network can be determined.

Different from reference [23], in this paper, a deep neural network predictor (DNNP) uses the historical velocity and the acceleration/brake pedal position as inputs to predict the future velocity in upcoming period of time. Besides, different from reference [21], in order to improve the accuracy of predictor, before the input data are delivered to neural network predictor, a state identifier is applied to identify the state of the input data. The state identifier uses the first order polynomial to fit the historical velocity, and the state of the input data is determined by both of the range of slope of the fitted polynomial and the signal of acceleration/brake. The classification rules for state of input data are shown in Table 1; the $\alpha 1$ and $\alpha 2$ are reference slope values which are determined by predictive effect. The "+" means the acceleration pedal signal is effective, and the "-" means the brake pedal signal is effective.
Some different single basic predictors based on deep neural deep network can be used for training according to the state of the input data, and all of the trained single basic predictors are applied to construct an integrated predictor. The single basic predictor scheme is shown in Figure 10, and the integrated predictor scheme for $\mathrm{P}^{2} \mathrm{MPC}$ is shown in Figure 11.

For accurate prediction output, deep neural networks predictor should be trained through a lot of training data. Training sample data consist of the 5 driving cycles of CSHVR, NEDC, 1015_6PRIUS, HWFET, and UNIF01, and these driving cycles are arranged randomly in each training sample to increase training information, as shown in Figure 12.

The training process uses every 6 historical velocities and the current acceleration/brake pedal position as the inputs and the next 5 velocities as the output label, where each time interval is $1 \mathrm{~s}$. Subsequently, the predictive velocity can be used to calculate the power demands in prediction horizon. In this paper, DNNP adopts 2 hidden layers and there are 12 nodes in each layer. In order to compare the accuracy between the single basic predictor and proposed integrated predictor, the root-mean-square error (RMSE) is applied. The calculation equation of RMSE in each second over prediction horizon is expressed as follows:

$$
\operatorname{RMSE}(i)=\sqrt{\frac{\sum_{i=1}^{P}\left(V_{p}(i)-V_{a}(i)\right)^{2}}{P}},
$$

where $V_{p}$ denotes the predictive velocity, $V_{a}$ denotes the actual velocity, $i$ denotes the $i$-th second in prediction horizon, and $P$ is the total seconds of prediction horizon. The overall RMSE over driving cycle is described as

$$
\operatorname{RMSE}=\frac{\sum_{i=1}^{N} \operatorname{RMSE}(i)}{N},
$$

where $N$ denotes the total amount of seconds in driving cycle. The compared results are shown in Table 2. The results indicate that the proposed integrated predictor can obtain better prediction performance.

In order to show the accuracy of the predictor in each second over prediction horizon, the calculation equation of RMSE for each second is expressed as follows:

$$
\operatorname{RMSE} \__{-} x=\sqrt{\frac{\sum_{i=1}^{N}\left(V_{p_{-} x}(i)-V_{a_{-} x}(i)\right)^{2}}{N}},
$$

where $V_{p_{-} x}$ denotes the predictive velocity in the $x$-th second in prediction horizon, $V_{a_{-} x}$ denotes the actual velocity in the $x$-th second in prediction horizon, and $i$ denotes the $i$-th second in driving cycle, $N$ denotes the total amount of seconds in driving cycle. The RMSEs between the predictive velocity and actual velocity in 1st, $2 \mathrm{nd}, 3 \mathrm{rd}$, 4th, and 5th seconds in prediction horizon are compared in Table 3. Based on the trained DNNP, the predictive velocity and actual velocity in the 1 st to 5 th seconds over prediction horizon are compared in Figure 13.

As shown in Figure 13 and Table 3, the prediction velocity in the 1st second of prediction horizon matches actual 


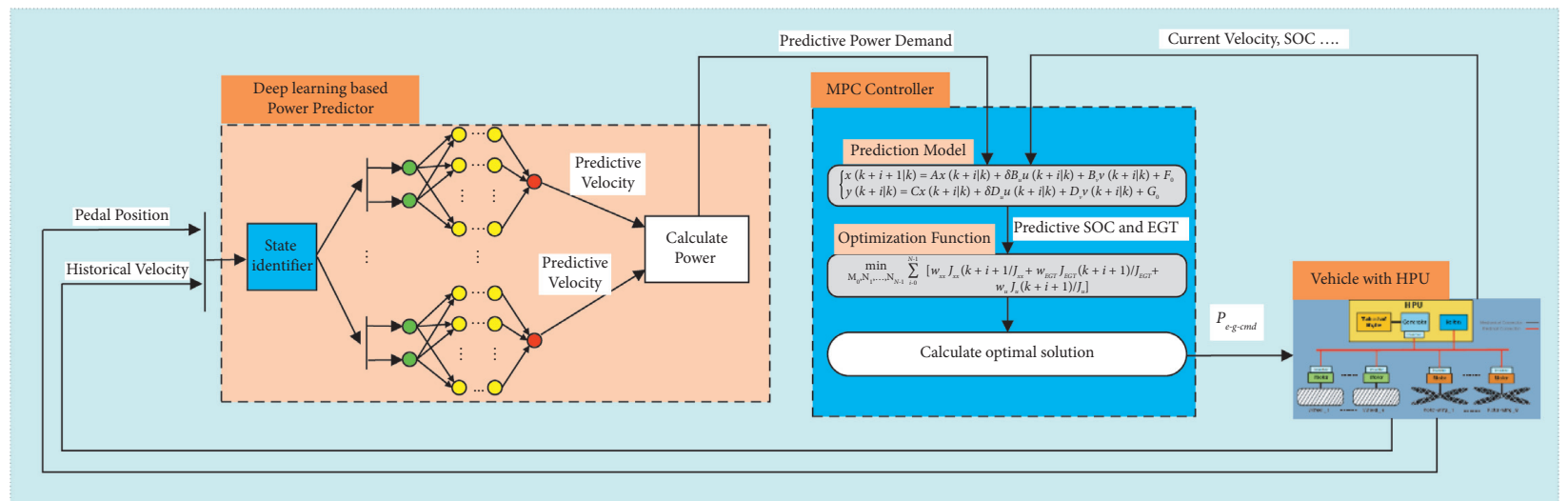

FIgURE 9: Power prediction-based MPC for energy management scheme.

TABle 1: Classification of state of input data.

Classification of states The range of slope of first order fitted polynomial for historical velocity Acceleration/brake pedal position

\begin{tabular}{lcc}
\hline 1 & $(\alpha 1,+\infty)$ & + \\
2 & $(\alpha 1,+\infty)$ & - \\
3 & {$[\alpha 2, \alpha 1]$} & + \\
4 & {$[\alpha 2, \alpha 1]$} & - \\
5 & $(-\infty, \alpha 2)$ & + \\
6 & $(-\infty, \alpha 2)$ & - \\
\hline
\end{tabular}

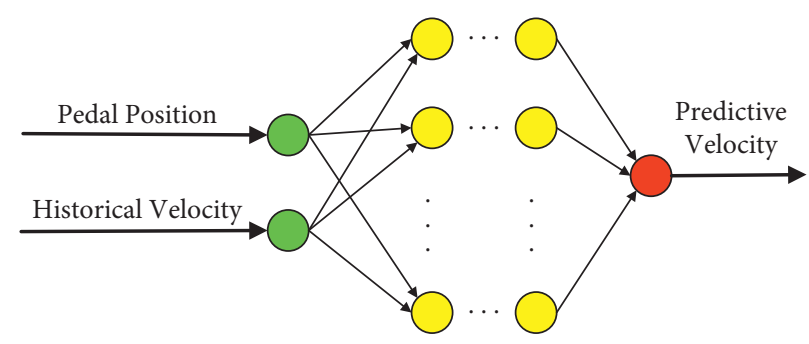

Figure 10: Single basic predictor scheme.

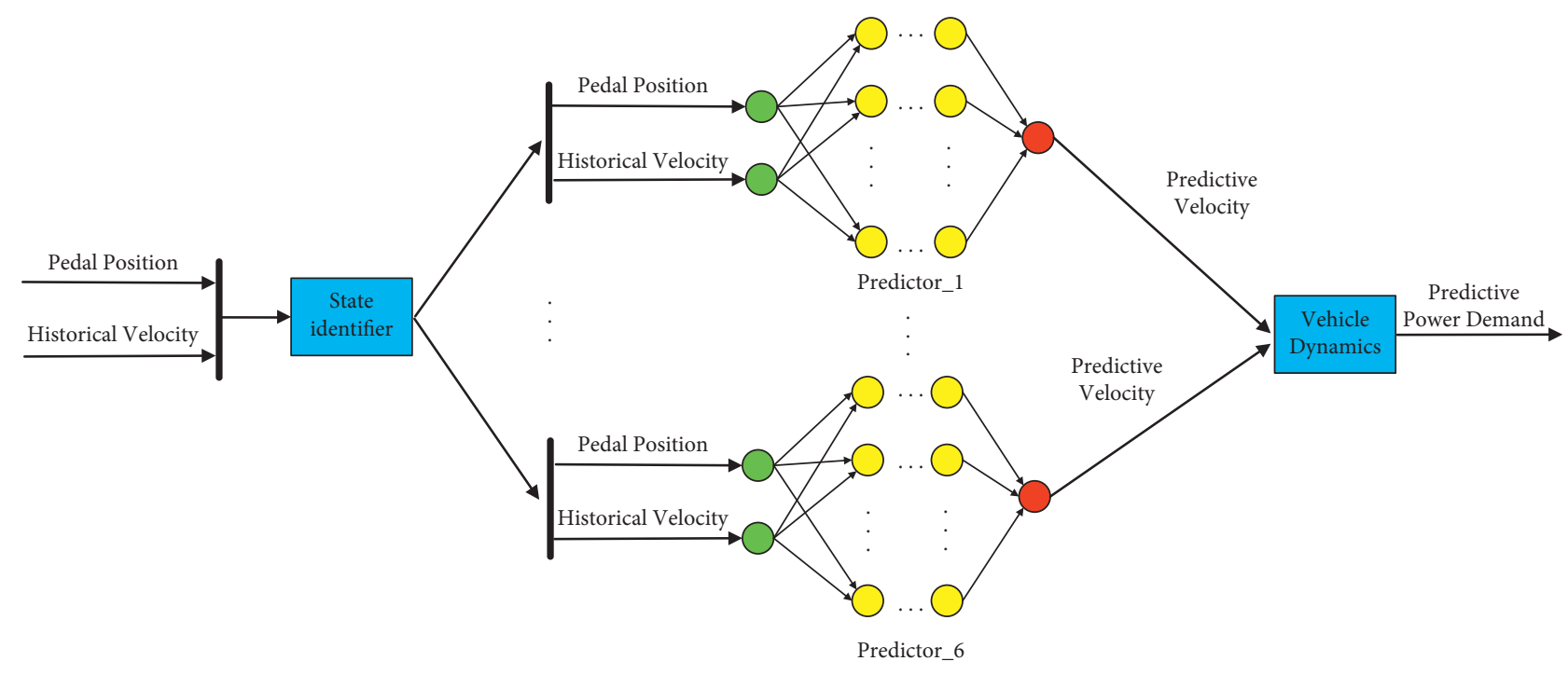

FIgURE 11: Proposed integrated predictor scheme for $\mathrm{P}^{2} \mathrm{MPC}$. 


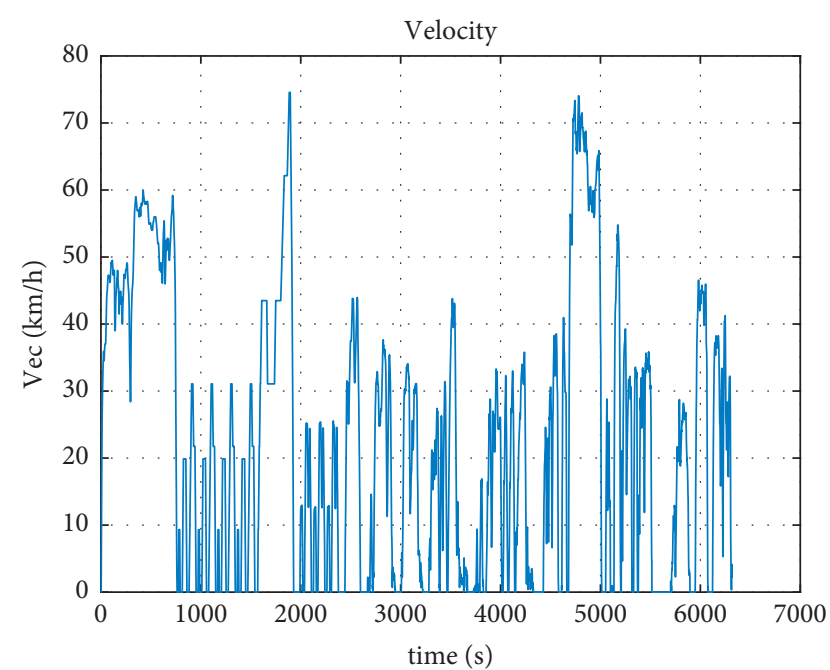

FIgURE 12: Training sample with multiple driving cycles.

TABLE 2: RMSE between single basic predictor and integrated predictor.

\begin{tabular}{lc}
\hline Method & RMSE $(\mathrm{km} / \mathrm{h})$ \\
\hline Single basic predictor & 1.1470 \\
Integrated predictor & 1.0009 \\
\hline
\end{tabular}

TABLE 3: RMSE between actual result and predictive result in each second.

\begin{tabular}{lc}
\hline The sample second in the prediction horizon & RMSE $(\mathrm{km} / \mathrm{h})$ \\
\hline 1st & 0.7365 \\
2nd & 0.8346 \\
3rd & 1.0469 \\
4th & 1.3150 \\
5th & 1.6026 \\
\hline
\end{tabular}

result more closely than that in the 5th second. The compared results show that the prediction accuracy decreases as the sampling moment in prediction horizon increases, and the longer prediction horizon is not necessary. The overall trend of prediction results is consistent with the variation trend of the actual results, and it also indicates the DNNP is suitable for the future power demand prediction of the vehicle in proper prediction horizon.

3.3. Prediction Model and Objective Function for $P^{2} M P C$. The control objectives of $\mathrm{P}^{2} \mathrm{MPC}$ are mainly to regulate SOC around reference value and to decrease the EGT of turboshaft engine, which contribute to improving the power quality and long engine life. Therefore, according to equation (8), the dynamic characteristics of the battery SOC are described by

$$
\operatorname{SOC}(t)=\frac{-U_{\text {ocv }}(t)+\sqrt{U_{\text {ocv }}^{2}(t)-4 R_{\text {int }}(t)\left(P_{\mathrm{de}}(t)-P_{e-g}(t)\right)}}{2 R_{\text {int }}(t) Q_{\text {batt }}} .
$$

The variation of $P_{\mathrm{de}}$ over the prediction horizon can be obtained by the prediction of DNNP. According to equation (6), the EGT of turboshaft engine is expressed as the following equation:

$$
\operatorname{EGT}(t)=\frac{1}{T}\left(K \eta P_{e-g}(t)-\operatorname{EGT}(t)\right) .
$$

The $\eta$ denotes the energy conversion efficiency between turboshaft engine and generator. According to equation (7), the $P_{e-g}$ satisfies the first order inertial process and can be expressed as

$$
T_{g} \dot{P}_{e-g}(t)+P_{e-g}(t)=P_{\mathrm{e}-\mathrm{g}-\mathrm{cmd}} .
$$

where $P_{\text {e-g-cmd }}$ denotes the reference control command and $P_{e-g}$ is the actual control variable which has been applied to the system. The nonlinear prediction model for $\mathrm{P}^{2} \mathrm{MPC}$ for the vehicle is expressed as follows:

$$
\left\{\begin{array}{l}
\dot{x}=f(x, u, v) \\
y=g(x, u, v)
\end{array}\right.
$$

where

$$
x=\left[\begin{array}{c}
\mathrm{SOC} \\
\mathrm{EGT}
\end{array}\right], u=\left[P_{\mathrm{e}-\mathrm{g}-\mathrm{cmd}}\right], v=\left[P_{\mathrm{de}}\right], y=\left[\begin{array}{c}
\mathrm{SOC} \\
\mathrm{EGT}
\end{array}\right],
$$

where $x$ is the state variable, $u$ is the control variable, $v$ is the measured input variable, and $y$ is the output variable.

The small variation of SOC from the reference value can contribute to the good power supply quality and long life of power battery. Therefore, the objective optimization function for SOC is expressed as follows:

$$
\int_{t_{0}}^{t_{f}} J_{\mathrm{soc}}(t)=\int_{t_{0}}^{t_{f}}\left(\operatorname{SOC}(t)-\mathrm{SOC}_{r}\right)^{2} \mathrm{~d} t .
$$

In addition, the low EGT can reduce the damage of components of turboshaft engine and extend the life of HPU. Therefore, the objective optimization function for EGT is expressed as follows:

$$
\int_{t_{0}}^{t_{f}} J_{\mathrm{EGT}}(t)=\int_{t_{0}}^{t_{f}} \mathrm{EGT}(t)^{2} \mathrm{~d} t .
$$

In addition, in order to reduce disturbance among the control sequences, the change of the control sequences is also concerned. The objective optimization function for the control sequences is expressed as follows:

$$
\int_{t_{0}}^{t_{f}} J_{u}(t)=\int_{t_{0}}^{t_{f}}\left(P_{e-g}(t)-P_{e-g 0}\right)^{2} \mathrm{~d} t .
$$

Different from the works in references [21-23], linear weighting method is applied to establish the multiobjective optimization function in this paper, and the multiobjective optimization function for $\mathrm{P}^{2} \mathrm{MPC}$ is described by 


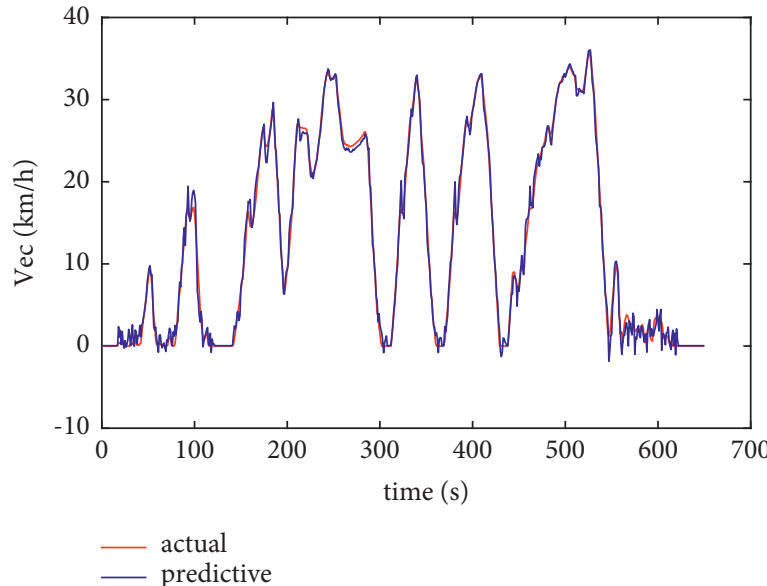

(a)

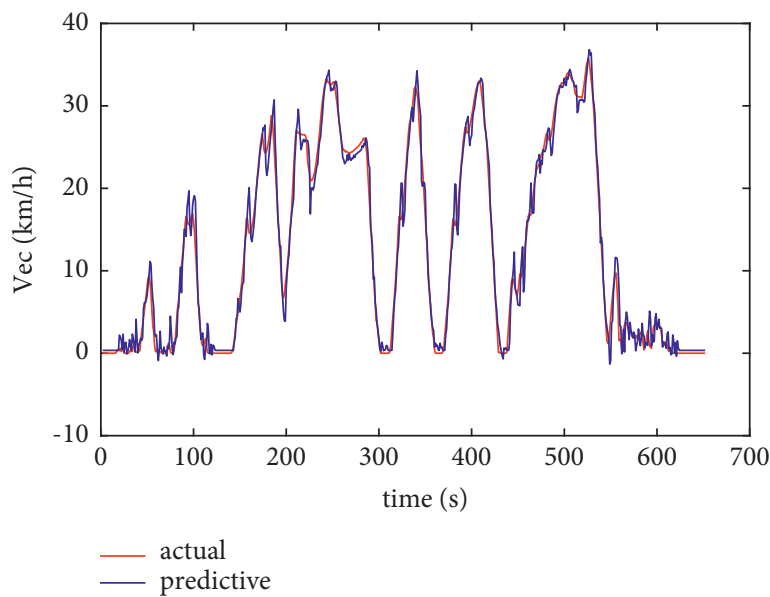

(c)

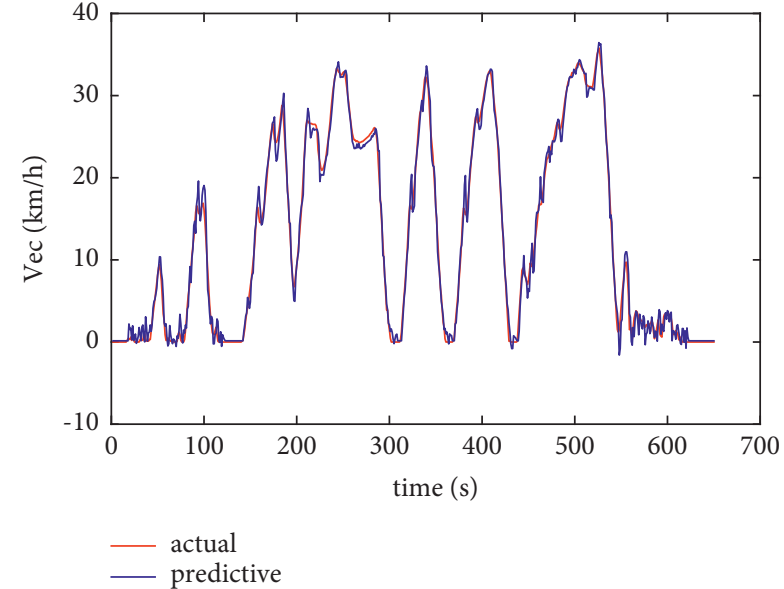

(b)

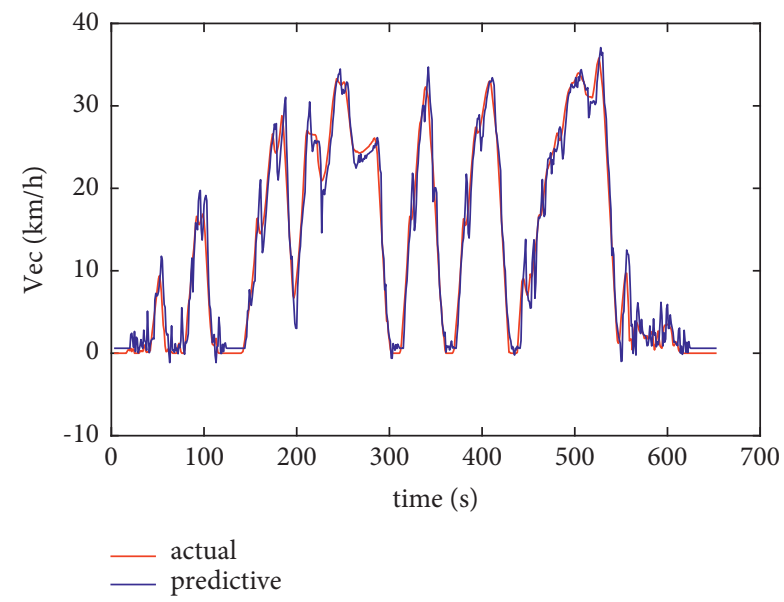

(d)

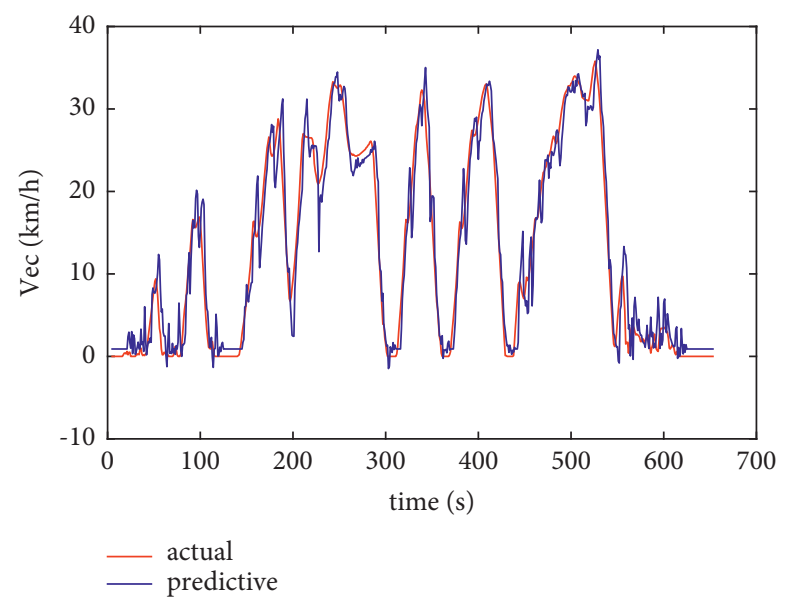

(e)

Figure 13: Comparison between predictive results and actual results. (a) Predictive velocity in 1st second. (b) Predictive velocity in 2nd second. (c) Predictive velocity in 3rd second. (d) Predictive velocity in 4th second. (e) Predictive velocity in 5th second. 


$$
\min J_{\text {cost }}=\min \int_{t_{0}}^{t_{f}}\left(W_{\mathrm{soc}} \frac{J_{\mathrm{soc}}(t)}{\bar{J}_{\mathrm{soc}}}+W_{\mathrm{EGT}} \frac{J_{\mathrm{EGT}}(t)}{\overline{\mathrm{EGTT}}_{\mathrm{ET}}}+W_{u} \frac{J_{u}(t)}{\bar{J}_{u}}\right) .
$$

In equations (20)-(22), where $P_{\mathrm{e}-\mathrm{g} 0}$ is the initial output power of HPU, $S O C_{r}$ is the SOC reference value, $W_{\text {soc }}$, $W_{\mathrm{EGT}}$, and $W_{u}$ are the weight coefficients, $\mathrm{t}_{0}$ is the starting time and $t_{f}$ is the ending time in the prediction horizon, and $\overline{J_{\mathrm{soc}}}, \overline{J_{\mathrm{EGT}}}, \overline{J_{u}}$ are the reference values for normalization. The control sequences can be obtained by minimizing the value of the objective cost function $J_{\text {cost }}$.

To improve the real-time performance of online optimization of $\mathrm{P}^{2} \mathrm{MPC}$, the Taylor expansion technology is applied for equation (18) to obtain the linear model of nonlinear prediction model and the linear model is expressed as

$$
\left\{\begin{array}{l}
\dot{x}=A x+\delta B_{u} u+B_{v} v+F_{0} \\
y=C x+\delta D_{u} u+D_{v} v+G_{0}
\end{array}\right.
$$

where

$$
\begin{aligned}
A & =\left(\frac{\partial f}{\partial x}\right)_{\left(x_{0}, u_{0}, v_{0}\right)}, \\
B_{u} & =\left(\frac{\partial f}{\partial u}\right)_{\left(x_{0}, u_{0}, v_{0}\right)}, \\
B_{v} & =\left(\frac{\partial f}{\partial v}\right)_{\left(x_{0}, u_{0}, v_{0}\right)}, \\
C & =\left(\frac{\partial g}{\partial x}\right)_{\left(x_{0}, u_{0}, v_{0}\right)}, \\
D_{u} & =\left(\frac{\partial g}{\partial u}\right)_{\left(x_{0}, u_{0}, v_{0}\right)}, \\
D_{v} & =\left(\frac{\partial g}{\partial v}\right)_{\left(x_{0}, u_{0}, v_{0}\right)}, \\
F_{0} & =f\left(x_{0}, u_{0}, v_{0}\right)-A x_{0}-B_{u} u_{0}-B_{v} v_{0}, \\
G_{0} & =g\left(x_{0}, u_{0}, v_{0}\right)-C x_{0}-D_{u} u_{0}-D_{v} v_{0} .
\end{aligned}
$$

Here, $u_{0}, \mathrm{x}_{0}$, and $v_{0}$ are the current state variables in current step, $u$ is $P_{e-g}$. According to equation (17) and the response characteristics of the first order inertial process, assume the control reference command $P_{\text {e-g-cmd }}$ does not change between current time $t_{k}$ and next time $t_{\mathrm{k}+1}$ in the prediction horizon, and the average value of $P_{\text {e-g-cmd }}$ is regarded as the actual applied control variable. Therefore, the correction factor $\delta$ is determined by

$$
\delta=\int_{0}^{t s}\left(1-e^{-t / T}\right) \mathrm{d} t,
$$

where the ts denotes time interval in the prediction horizon of MPC. To improve the calculation speed, the discrete model of linear prediction model is obtained and expressed as $\left\{\begin{array}{l}x(k+i+1 \mid k)=A x(k+i \mid k)+\delta B_{u} u(k+i \mid k)+B_{v} v(k+i \mid k)+F_{0}, \\ y(k+i \mid k)=C x(k+i \mid k)+\delta D_{u} u(k+i \mid k)+D_{v} v(k+i \mid k)+G_{0},\end{array}\right.$

where $k$ represents the current step and $k+i$ represents the $i$-th step in prediction horizon. The discrete objective cost function is expressed as

$$
\begin{aligned}
\min _{u_{0}, u_{1}, \ldots, u_{N-1}} J= & \min _{u_{0}, u_{1}, \ldots, u_{N-1}} \sum_{i=0}^{N-1}\left[W_{\mathrm{soc}} \frac{J_{\mathrm{soc}}(k+i+1)}{\overline{J_{\mathrm{soc}}}}\right. \\
& \left.+W_{\mathrm{EGT}} \frac{J_{\mathrm{EGT}}(k+i+1)}{\overline{J_{\mathrm{EGT}}}}+W_{u} \frac{J_{u}(k+i+1)}{\overline{J_{u}}}\right] .
\end{aligned}
$$

The interior-point method can be applied to solve equation (28) to obtain the control sequences, and the first element in the control sequences is regarded as the control variable to be employed for the HPU.

\section{Results and Discussion}

4.1. Simulation Validation of Turboshaft Engine Dynamics Model. Turboshaft engine is different from the diesel engine which is widely adopted by hybrid vehicle, and it plays a vital role in the research on EMS. For verifying the accuracy of the turboshaft engine model based on the proposed method, according to the experimental data and modeling process in Section 2.2.1, the simulation model of turboshaft engine has been established and the simulation results are compared with experimental data in Figures 14-16.

As shown in Figure 14, the simulation input is experimental fuel flow data in engine starting progress; the output speed results of model show that the maximum rotate speed relative error between the model output and the experimental data is $4.2 \%$ in the engine starting process. As shown in Figures 15 and 16, the simulation inputs are experimental fuel flow data and outputs are engine torque and EGT. The simulation torque results show that the maximum relative error between the output steady-state torque of model and the experimental data is $5 \%$, and the dynamics error of torque is larger than steady-state error, but the dynamics tendency agrees well with the experimental data. Furthermore, the simulation EGT results show that the maximum relative error between the model output EGT and the experimental data is $1.7 \%$ in the engine loading process. The simulation results show that the turboshaft engine model by the proposed dynamics coefficient modeling method in this paper has good accuracy, and the proposed data-driven method is very efficient and practical for the modeling of turboshaft engine dynamics.

4.2. Simulation of EMS Based on $P^{2} M P C$. In order to verify the performance achieved by the proposed EMS based on $\mathrm{P}^{2} \mathrm{MPC}$, the simulation model for the vehicle model with HPU in land mode is established in MATLAB/SIMULINK based on the subsystem models such as turboshaft engine and battery. Besides, the UDDS driving cycle is used and the 


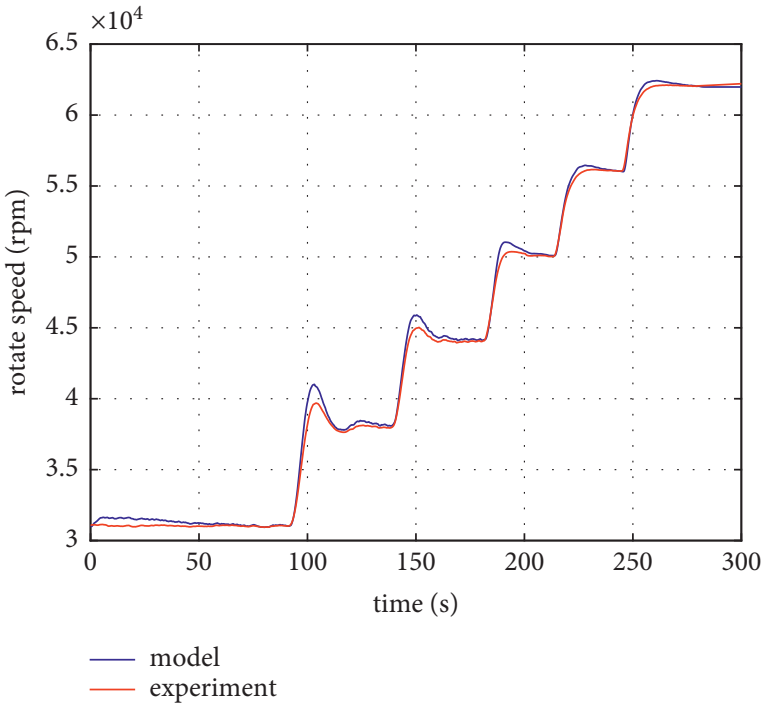

(a)

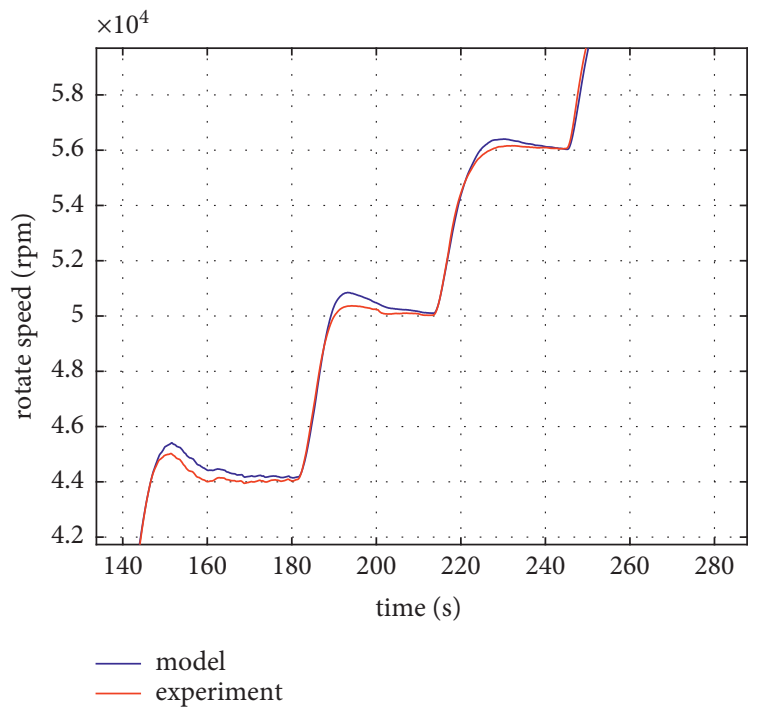

(b)

FIgURe 14: Rotate speed simulation results. (a) Rotate speed results in starting process. (b) Rotate speed results during $140 \mathrm{~s}$ to $280 \mathrm{~s}$.

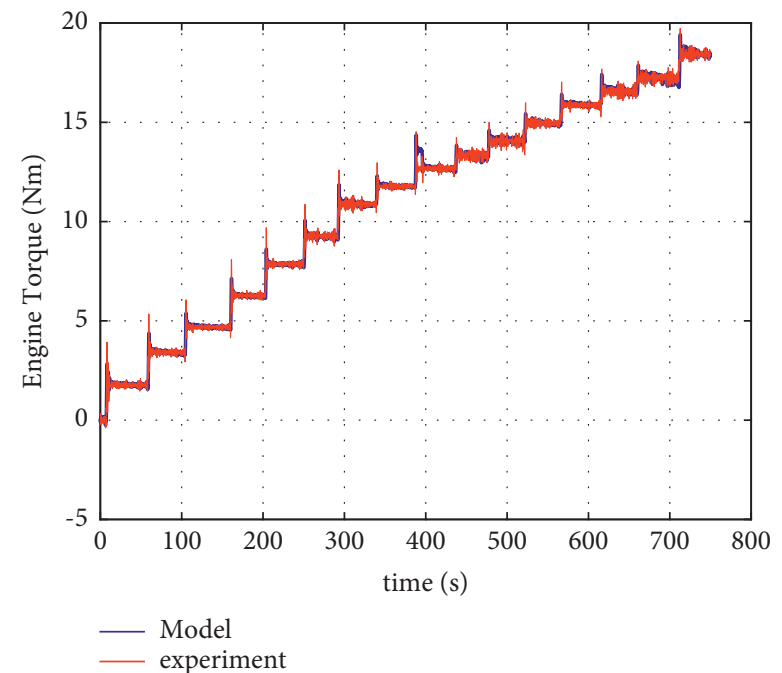

(a)

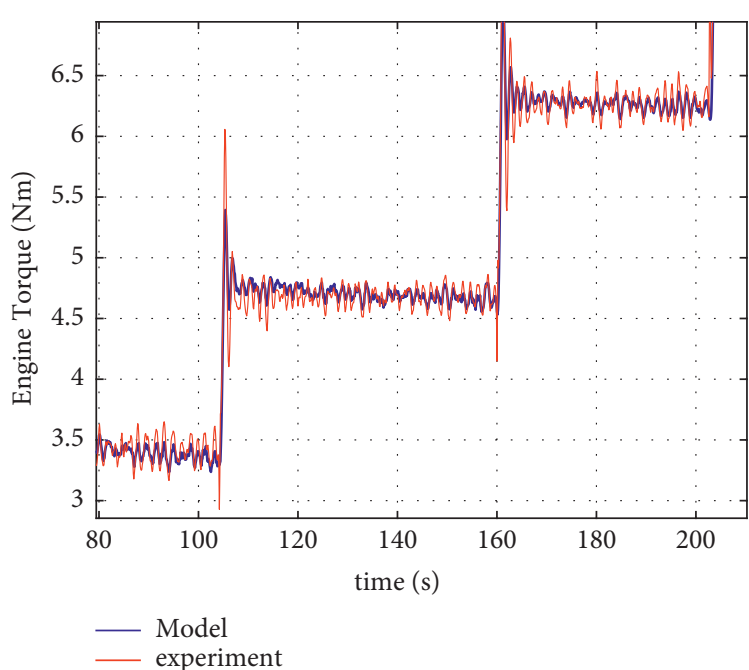

(b)

Figure 15: Torque simulation results. (a) Torque results in loading process. (b) Torque results during $80 \mathrm{~s}$ to $200 \mathrm{~s}$.

driver model is also modelled by PI control method to simulate the power demand. The main parameters of model are shown in Table 4, and the simulation results of the proposed EMS are shown as follows. As shown in Figure 17(a), the performance of the velocity tracking between the velocity from the vehicle simulation model and the reference velocity from the UDDS driving cycle is good. The positive value of the output power $\mathrm{P}_{\text {motor }}$ of distributed drive motors in Figure 17(b) means the power from HPU is delivered to increase or maintain the velocity of the vehicle, and the negative value of power indicates the power is recovered to reduce the velocity.
4.2.1. Comparison between Conventional MPC and $P^{2} M P C$. The simulation for comparing the control performance between the conventional MPC and $\mathrm{P}^{2}$ MPC has been carried out. In this paper, the prediction horizon is set as the future 5 seconds. $P_{\text {dep_x }}$ represents the predictive power demand in $x$-th second in the prediction horizon. Besides, in order to reveal the effect of the predictive power demands on the $\mathrm{P}^{2} \mathrm{MPC}$, the different configurations of predictive power demand over prediction horizon in MPC approach are set, and the simulations of mean relative deviation of SOC and EGT are compared. The simulation results of conventional MPC method are used as the 


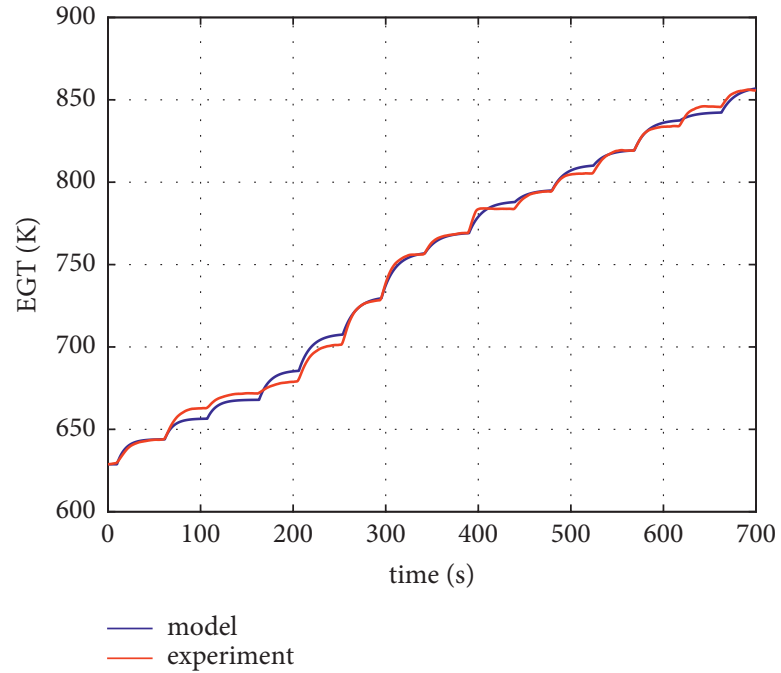

(a)

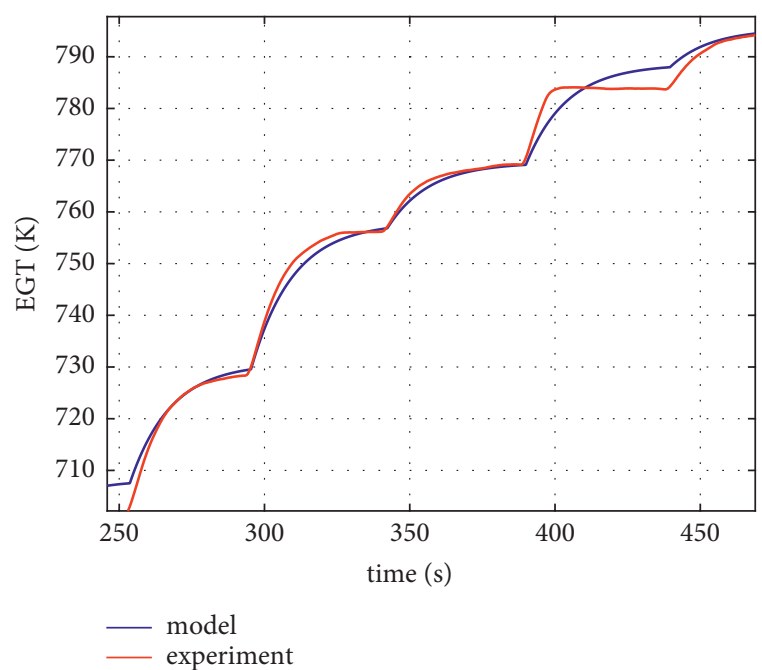

(b)

FIGURE 16: EGT simulation results. (a) EGT results in loading process. (b) EGT results during $250 \mathrm{~s}$ to $450 \mathrm{~s}$.

TABLE 4: Main parameters of HPU.

Parameters

Value

Rated power of turboshaft engine $(\mathrm{kW})$

120

Rated speed of turboshaft engine (rpm)

62000

Rated power of generator $(\mathrm{kW})$

116

Rated speed of generator (rpm)

5800

Max speed of generator (rpm)

12,000

Rated power of distributed drive motor $(\mathrm{kW})$

$30 \times 4$

Rated speed of distributed drive motor (rpm)

3500

Rated voltage of battery (V)

504

Rated capacity of battery (Ah)
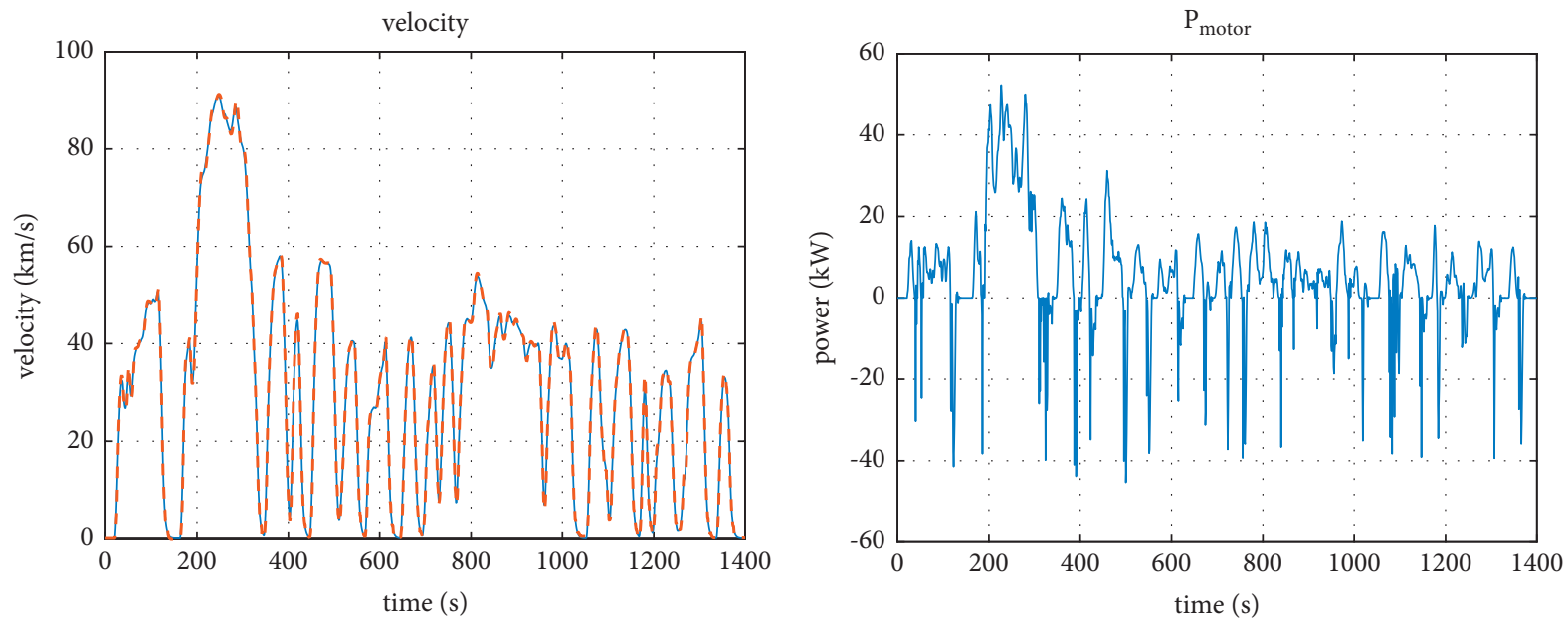

- UDDS ref

- - - Model vec

(a)

(b)

FIGURE 17: Simulation result of velocity and output power of motors. (a) Velocity tracking. (b) Output power of distributed drive motors. 
TABLE 5: Simulation results of different configuration of predictive power demands for the proposed predictor which adopts velocity and pedal position as inputs.

\begin{tabular}{|c|c|c|c|c|c|c|c|}
\hline \multirow[t]{2}{*}{ No. } & \multicolumn{5}{|c|}{$\begin{array}{l}\text { Power demand configuration in } \\
\text { prediction horizon }\end{array}$} & \multicolumn{2}{|c|}{$\begin{array}{l}\text { Increased mean } \\
\text { relative error } \\
\text { compared to } \\
\text { conventional } \\
\text { MPC method } \\
(\%)\end{array}$} \\
\hline & $1 \mathrm{st}$ & 2nd & $3 \mathrm{rd}$ & 4 th & 5 th & SOC & EGT \\
\hline 1 & $P_{\mathrm{de} 0}$ & $P_{\mathrm{de} 0}$ & $P_{\mathrm{de} 0}$ & $P_{\mathrm{de} 0}$ & $P_{\mathrm{de} 0}$ & - & - \\
\hline 2 & $P_{\text {dep_1 }}$ & $P_{\text {dep_1 }}$ & $P_{\text {dep_1 }}$ & $P_{\text {dep_1 }}$ & $P_{\text {dep_1 }}$ & -0.4938 & 0.0001 \\
\hline 3 & $P_{\text {dep_1 }}$ & $P_{\text {dep_2 }}$ & $P_{\text {dep } \_2}$ & $P_{\text {dep_2 }}$ & $P_{\text {dep } \_2}$ & -0.4465 & 0.0013 \\
\hline 4 & $P_{\text {dep_1 }}$ & $P_{\text {dep_2 }}$ & $P_{\text {dep } \_3}$ & $P_{\text {dep } \_3}$ & $P_{\text {dep } \_3}$ & -0.4906 & 0.0015 \\
\hline 5 & $P_{\text {dep_1 }}$ & $P_{\text {dep_2 }}$ & $P_{\text {dep } \_3}$ & $P_{\text {dep_4 }}$ & $P_{\text {dep } \_4}$ & -0.5033 & 0.0016 \\
\hline 6 & $P_{\text {dep_1 }}$ & $P_{\text {dep_2 }}$ & $P_{\text {dep } \_3}$ & $P_{\text {dep_ } \_4}$ & $P_{\text {dep } \_5}$ & -0.5042 & 0.0016 \\
\hline
\end{tabular}

TABLE 6: Simulation results of different configuration of predictive power demands for the predictor which only adopts velocity as inputs.

\begin{tabular}{|c|c|c|c|c|c|c|c|}
\hline \multirow[t]{2}{*}{ No. } & \multicolumn{5}{|c|}{$\begin{array}{l}\text { Power demand configuration in } \\
\text { prediction horizon }\end{array}$} & \multicolumn{2}{|c|}{$\begin{array}{l}\text { Increased mean } \\
\text { relative error } \\
\text { compared to } \\
\text { conventional } \\
\text { MPC method }(\%)\end{array}$} \\
\hline & $1 \mathrm{st}$ & 2nd & $3 \mathrm{rd}$ & 4th & 5 th & SOC & EGT \\
\hline 1 & $P_{\mathrm{de} 0}$ & $P_{\mathrm{de} 0}$ & $P_{\mathrm{de} 0}$ & $P_{\mathrm{de} 0}$ & $P_{\mathrm{de} 0}$ & - & - \\
\hline 2 & $P_{\text {dep_1 }}$ & $P_{\text {dep_1 }}$ & $P_{\text {dep_1 }}$ & $P_{\text {dep_1 }}$ & $P_{\text {dep_1 }}$ & -0.2723 & -0.0033 \\
\hline 3 & $P_{\text {dep_1 }}$ & $P_{\text {dep } \_2}$ & $P_{\text {dep } \_2}$ & $P_{\text {dep_2 }}$ & $P_{\text {dep_2 }}$ & 0.3092 & -0.0136 \\
\hline 4 & $P_{\text {dep } \_1}$ & $P_{\text {dep_2 }}$ & $P_{\text {dep } \_3}$ & $P_{\text {dep_3 }}$ & $P_{\text {dep_3 } 3}$ & 0.2978 & -0.0132 \\
\hline 5 & $P_{\text {dep_1 }}$ & $P_{\text {dep } \_2}$ & $P_{\text {dep } \_3}$ & $P_{\text {dep_4 }}$ & $P_{\text {dep } \_4}$ & 0.2985 & -0.0130 \\
\hline 6 & $P_{\text {dep } \_1}$ & $P_{\text {dep } \_2}$ & $P_{\text {dep_3 }}$ & $P_{\text {dep } \_4}$ & $P_{\text {dep } \_5}$ & 0.2958 & -0.0129 \\
\hline
\end{tabular}

reference in Table 5. Besides, in order to better demonstrate the advantage of the proposed predictor in this paper, the simulations for the predictor designed in reference [23] where only historical velocity is used as input without the pedal position are carried out, and the results are shown in Table 6.

As shown in Table 5, the No. 1 configuration shows the results of the conventional MPC where the power demands over the prediction horizon are assumed to be constant $P_{\mathrm{de} 0 \text {, }}$ which is the power demand in the current calculation step. No. 2-No. 6 configurations show the simulation results of $\mathrm{P}^{2} \mathrm{MPC}$. As shown in Table 5, compared to conventional MPC, the increased mean relative errors of SOC of different power demand configurations for $\mathrm{P}^{2} \mathrm{MPC}$ are all negative, which suggest the mean relative error of SOC by $\mathrm{P}^{2} \mathrm{MPC}$ is smaller than that by conventional MPC. Besides, the mean relative errors of EGT by $\mathrm{P}^{2} \mathrm{MPC}$ increase a little, which are tolerable considering the large decrease in the mean relative errors of SOC. The results show that compared to conventional MPC, the higher control performance can be obtained by the proposed $\mathrm{P}^{2} \mathrm{MPC}$.

As shown in Table 6, due to low accuracy of the predictor without pedal position as input, only No. 2 power demand configuration can achieve better control performance than conventional MPC; the worse control performance of the predictor without pedal position as input is obvious compared with the results in Table 5 where the predictor of $\mathrm{P}^{2} \mathrm{MPC}$ adopts historical velocity and pedal position as inputs, which also indicate the advantage of the proposed power predictor.

Besides, as shown in Table 5, the control performances of No. 3 and No. 4 configurations are worse than that of No. 2 configuration, and the control performances of No. 5 and No. 6 configurations are little better. In addition, as shown in Table 6, the increased mean relative error of SOC of the No. 2 configuration, where the power demands are assumed to be constant $P_{\text {dep } \_1}$ over the prediction horizon, is the smallest compared with No. 3-No. 6. The obvious better control performance cannot be furthermore obtained although more predictive power demand results are used over prediction horizon. The reason for the obvious better control performance cannot be obtained is that the prediction error increases with the lapse of time over the prediction horizon. According to Section 3.2 , the predicted error of the predictive velocity in the first second over the prediction horizon is the smallest, therefore predictive power demand $P_{\text {dep_ } 1}$ is closer to the actual power demand in the future, thus the No. 2 configuration of power demands in Tables 5 and 6 can achieve the good performance most possibly. It indicates that the predictive results in the time steps which are closer from the current time moment can improve control performance better. Based on the above analysis, the power predictor of $\mathrm{P}^{2} \mathrm{MPC}$-based EMS only predicts the power demand in the next second to reduce the calculation time cost, and the No. 2 configuration of power demands in Table 5 is adopted in the calculation of optimal control.

4.2.2. Weight Coefficient of $P^{2} M P C$. In order to analyze the effect of weight coefficient value on the performance of the proposed EMS, different weight coefficient values $W_{\text {soc }}$, $W_{\mathrm{EGT}}$, and $W_{u}$ are set in multiobjective function according to equation (28). According to Section 3.3, the linear weighting method is used to set the values of $W_{\text {soc }}, W_{\text {EGT }}$, and $W_{u}$. The sum of weight coefficient satisfies the following equation:

$$
w_{\mathrm{soc}}+w_{\mathrm{EGT}}+w_{u}=1
$$

In this paper, maintaining SOC around the reference value, low EGT and small disturbance between control sequences are concerned. For comparing the control performance, the following 5 indexes are introduced: the maximum relative error (MARE) of SOC from the reference value, the mean relative error (MERE) of SOC from the reference value, the MARE of EGT from the reference value, the MERE of EGT from the reference value, and the fluctuation coefficient (FC) of turboshaft engine power. The fluctuation coefficient of turboshaft engine power $h_{\mathrm{fc}}$ is expressed as follows:

$$
h_{f c}=\frac{\sum_{i=1}^{N}\left|P_{e}(i+1)-P_{e}(i)\right|}{\sum_{i=1}^{N}\left|P_{e}(i)\right|},
$$

where $N$ represents the total samples of simulation results, $i$ represents the $\mathrm{i}$-th step, and $P_{e}$ denotes the engine power. In order to compare the effect of the different 
TABLE 7: Configuration of weight coefficient.

\begin{tabular}{lccc}
\hline No. & $W_{\text {soc }}$ & $W_{u}$ & $W_{\text {EGT }}$ \\
\hline 1 & 0.1 & 0.8 & 0.1 \\
2 & 0.3 & 0.6 & 0.1 \\
3 & 0.5 & 0.4 & 0.1 \\
4 & 0.7 & 0.2 & 0.1 \\
5 & 0.2 & 0.6 & 0.2 \\
6 & 0.3 & 0.4 & 0.3 \\
7 & 0.4 & 0.2 & 0.4 \\
\hline
\end{tabular}
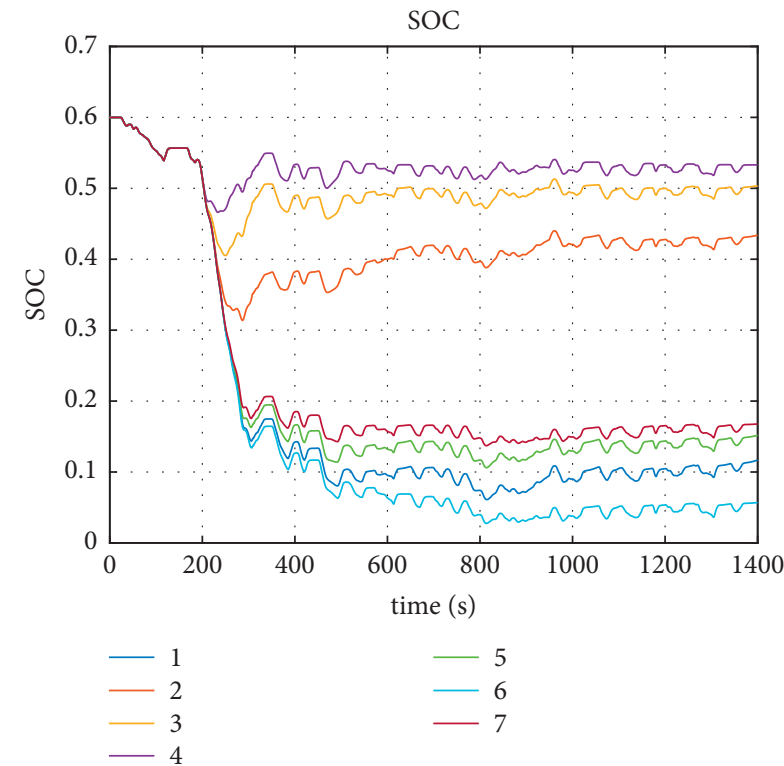

(a)
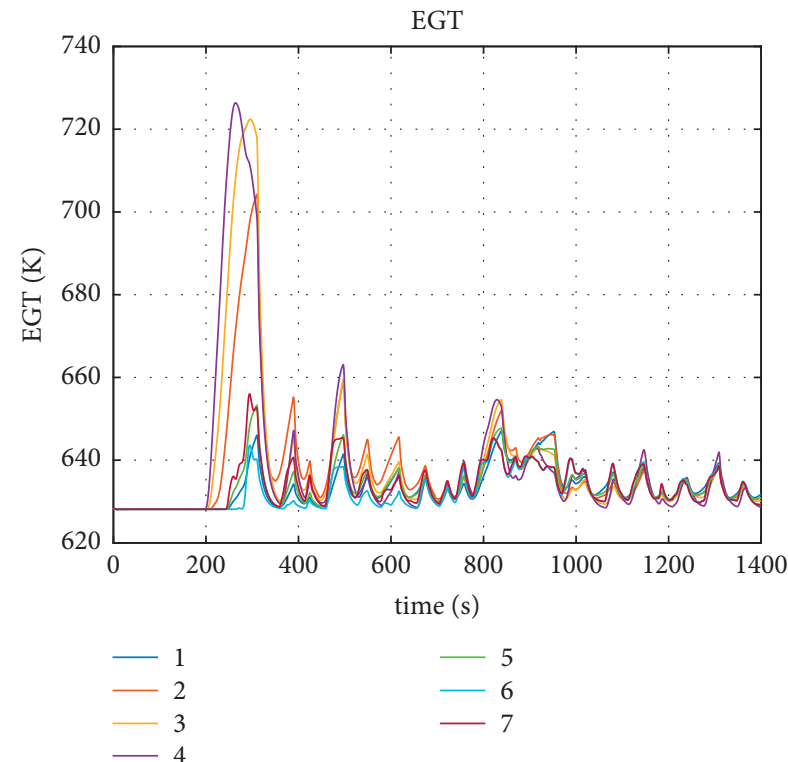

(b)

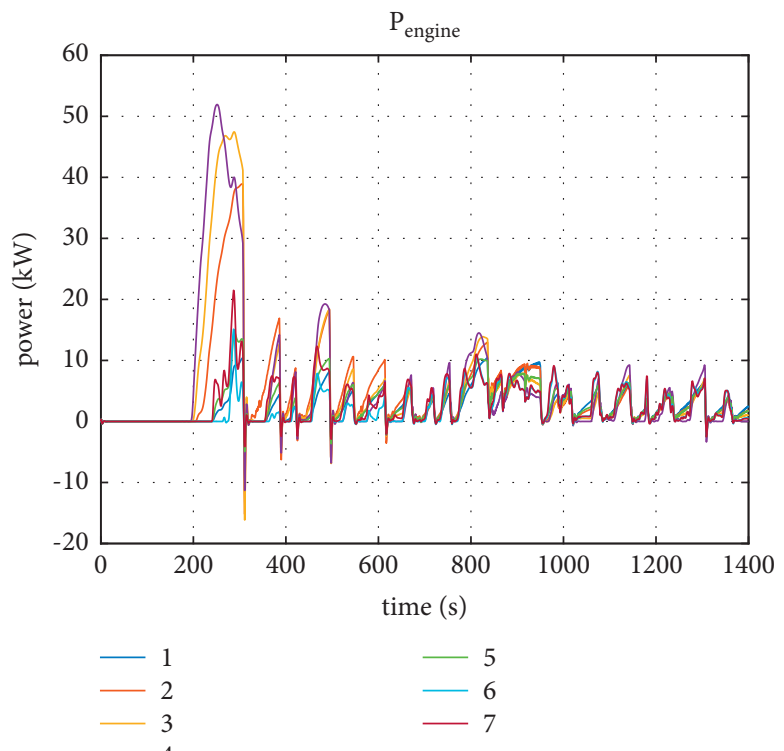

(c)

FIGURE 18: Simulation results comparison. (a) SOC of power battery. (b) EGT of turboshaft engine. (c) Output power of turboshaft engine. 
TABLE 8: Simulation results comparison.

\begin{tabular}{lccccc}
\hline No. & MARE of SOC $(\%)$ & MERE of SOC $(\%)$ & MARE of EGT (\%) & MERE of EGT (\%) & FC of engine power \\
\hline 1 & 89.8138 & 69.3692 & 3.0456 & 0.8324 & 0.0994 \\
2 & 47.7098 & 28.8055 & 12.1425 & 1.5549 & 0.0840 \\
3 & 32.4587 & 16.9455 & 15.0326 & 1.7097 & 0.0729 \\
4 & 22.3044 & 11.6822 & 15.6631 & 1.7696 & 0.0720 \\
5 & 82.3143 & 64.6012 & 4.0291 & 0.9064 & 0.0941 \\
6 & 78.9973 & 62.6751 & 4.2116 & 0.9272 & 0.0934 \\
7 & 77.1438 & 61.7034 & 4.4624 & 0.9348 & 0.1138 \\
\hline
\end{tabular}

TABle 9: Configuration of weight coefficient.

\begin{tabular}{lccc}
\hline No. & $W_{\text {soc }}$ & $W_{u}$ & $W_{\text {EGT }}$ \\
\hline 1 & 0.1 & 0.85 & 0.05 \\
2 & 0.2 & 0.75 & 0.05 \\
3 & 0.3 & 0.65 & 0.05 \\
4 & 0.4 & 0.55 & 0.05 \\
5 & 0.5 & 0.45 & 0.05 \\
6 & 0.6 & 0.35 & 0.05 \\
7 & 0.7 & 0.25 & 0.05 \\
8 & 0.8 & 0.15 & 0.05 \\
9 & 0.9 & 0.05 & 0.05 \\
\hline
\end{tabular}
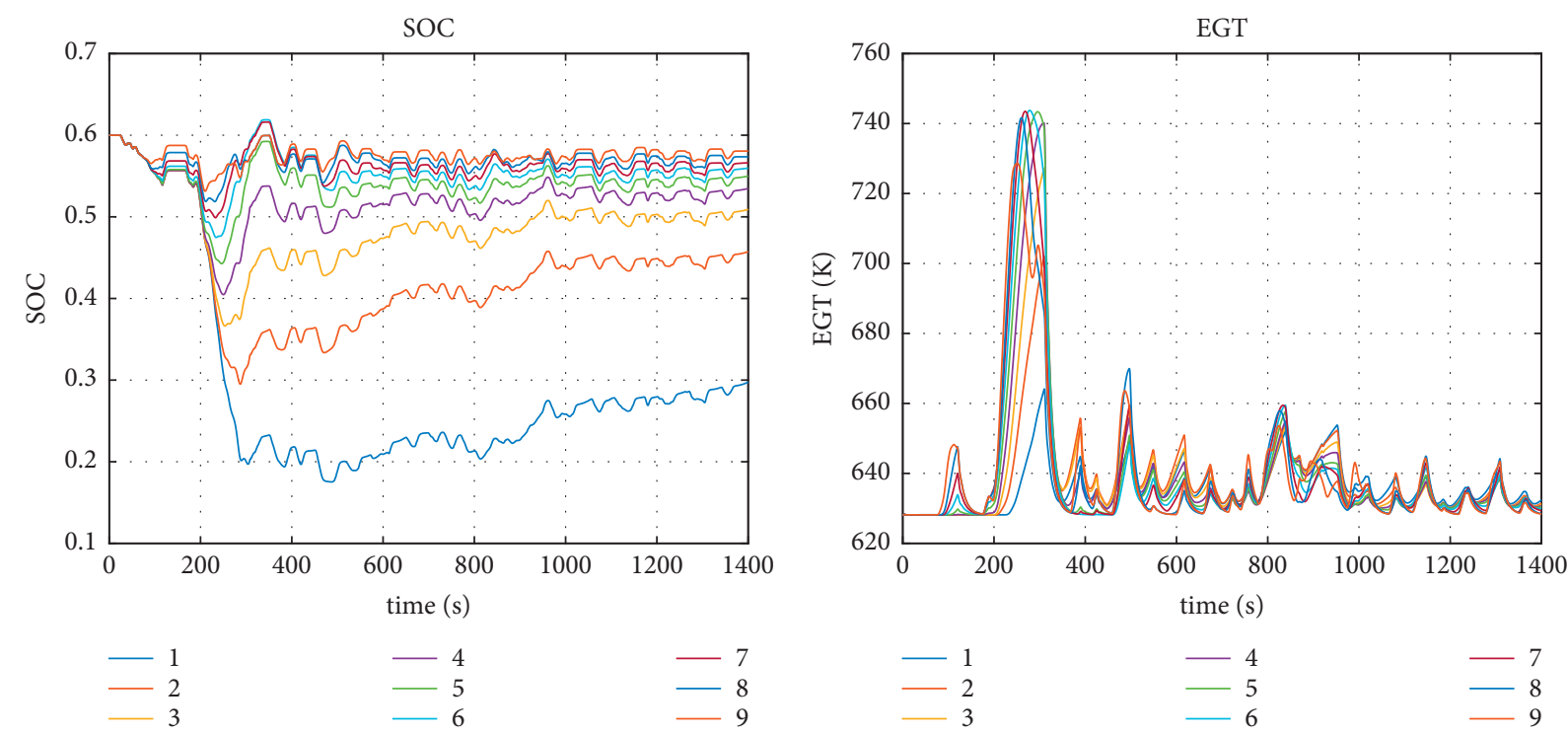

-4
-5
-6

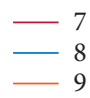

(a)

(b)

FIGURE 19: Continued. 


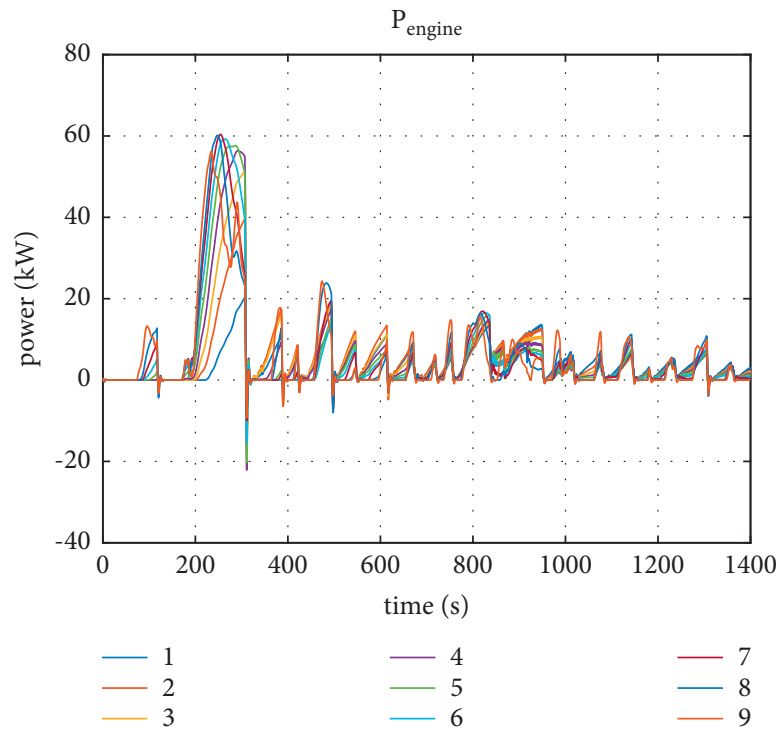

(c)

FIGURE 19: Simulation results comparison. (a) SOC of power battery. (b) EGT of turboshaft engine. (c) Output power of turboshaft engine.

TABLE 10: Simulation results comparison.

\begin{tabular}{lccccc}
\hline No. & MARE of SOC $(\%)$ & MERE of SOC $(\%)$ & MARE of EGT (\%) & MERE of EGT (\%) & FC of engine power \\
\hline 1 & 70.7978 & 51.1322 & 5.7555 & 1.2532 & 0.0963 \\
2 & 50.8427 & 28.4250 & 11.7985 & 1.6233 & 1.7401 \\
3 & 38.9488 & 18.5355 & 15.8013 & 1.7958 & 0.0889 \\
4 & 32.5395 & 13.1973 & 17.8563 & 1.8258 & 0.0815 \\
5 & 26.2150 & 9.7581 & 18.3720 & 1.8438 & 0.0742 \\
6 & 20.8709 & 7.6204 & 18.4334 & 1.8552 & 0.0676 \\
7 & 16.8339 & 6.3128 & 18.3871 & 1.8728 & 0.0691 \\
8 & 13.5561 & 5.2069 & 18.0982 & 1.8883 & 0.0769 \\
9 & 11.4335 & 4.0963 & 16.0255 & & 0.0884 \\
\hline
\end{tabular}

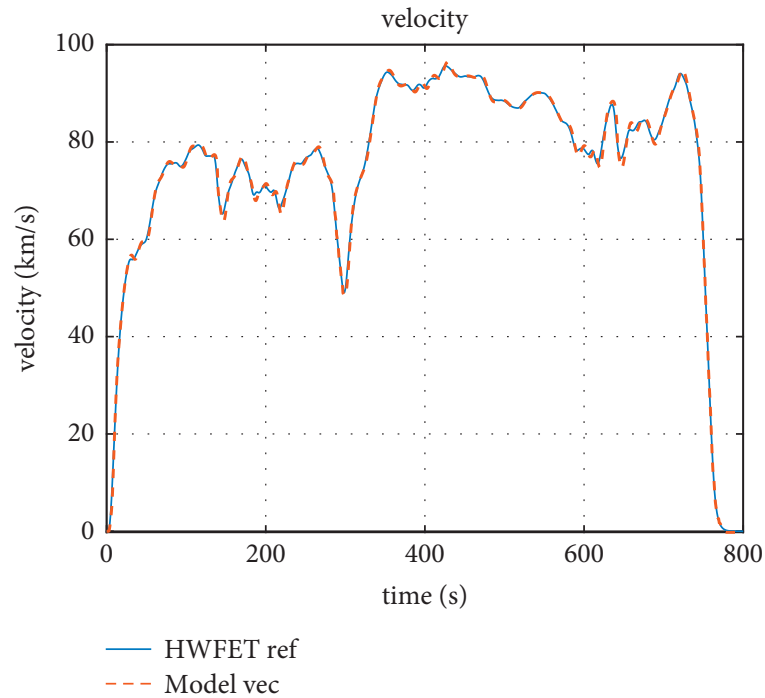

(a)

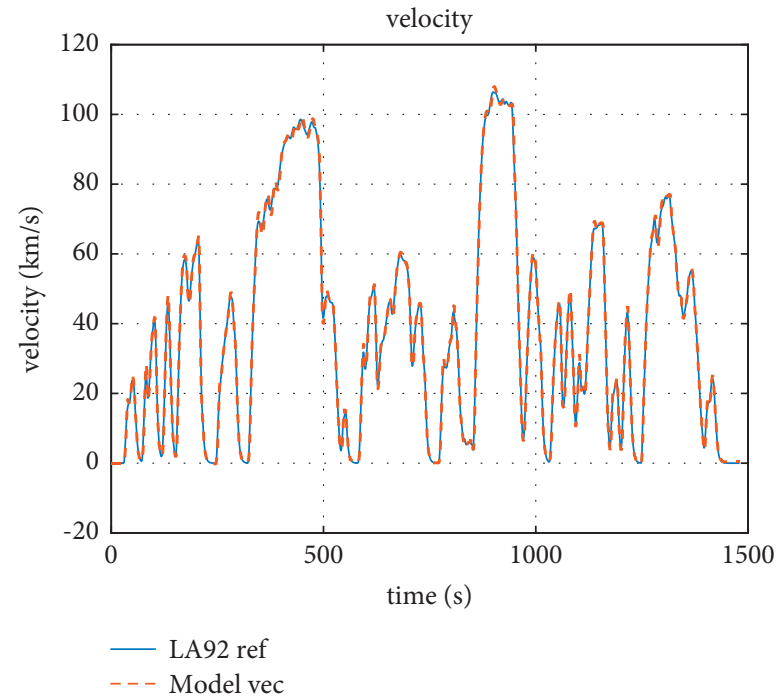

(b)

FIgure 20: Driving cycles. (a) HWFET. (b) LA92. 


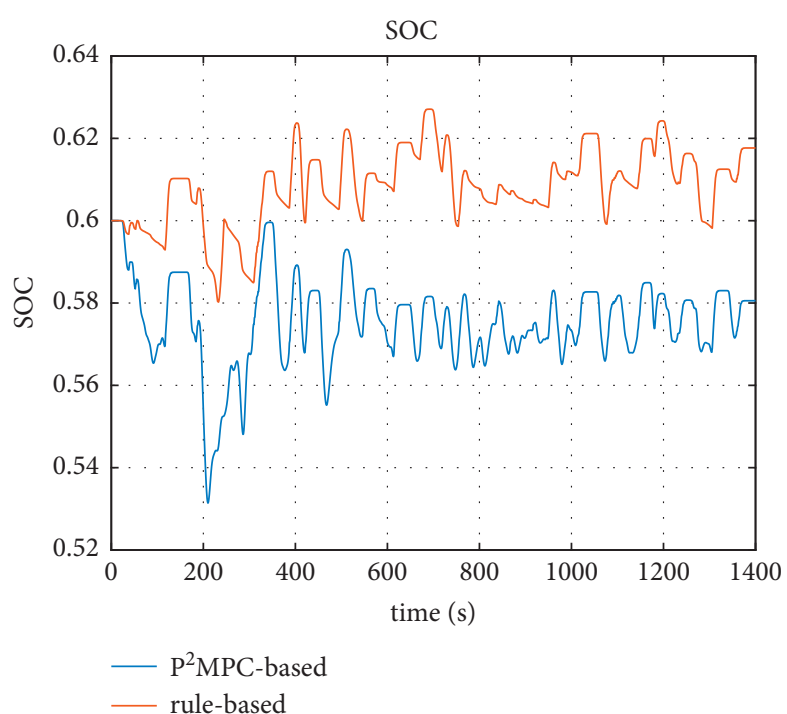

(a)

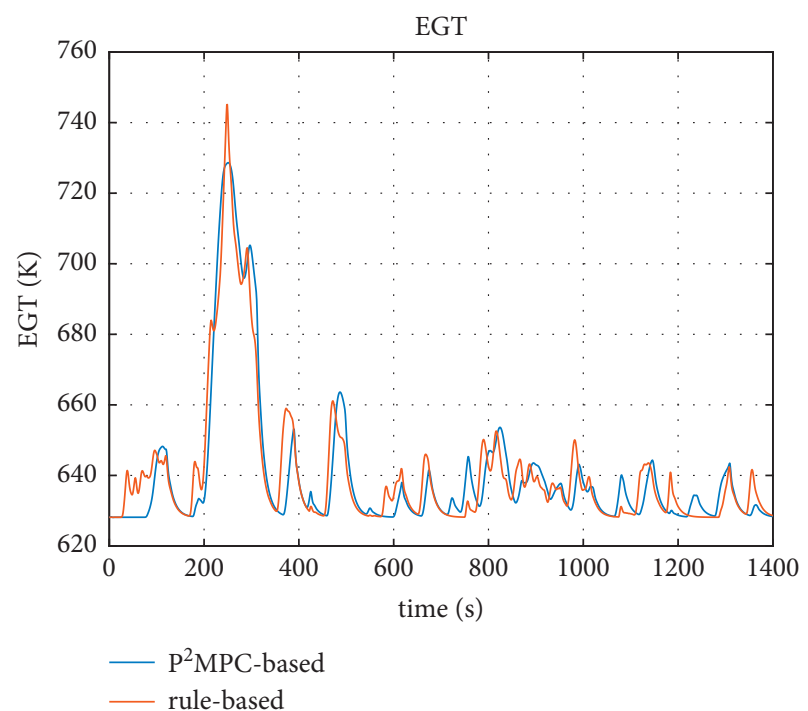

(b)

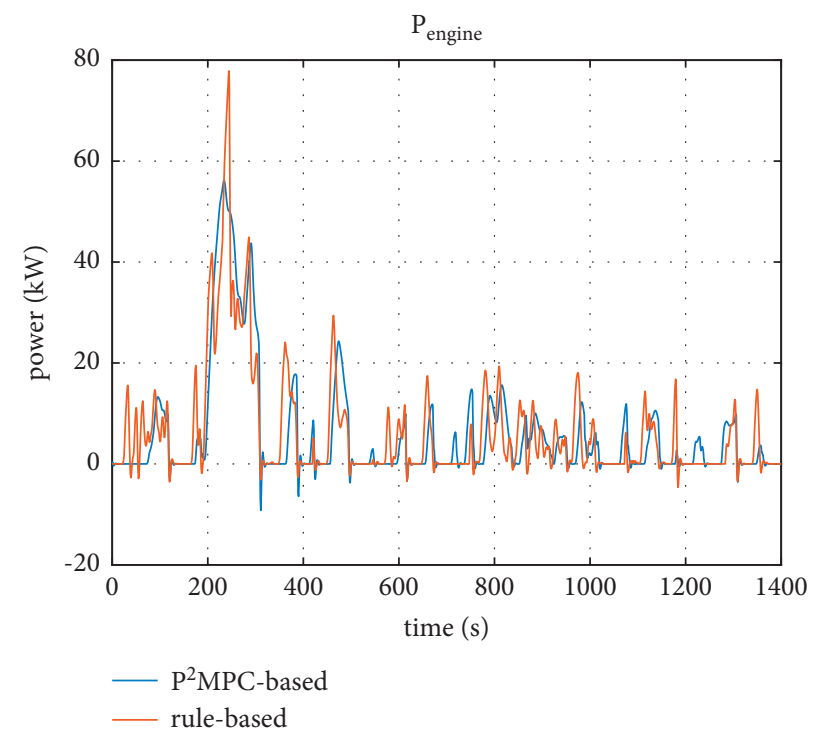

(c)

FIGURE 21: Simulation results comparison based on UDDS. (a) SOC of power battery. (b) EGT of turboshaft engine. (c) Output power of turboshaft engine.

weight coefficients in the multiobjective function in equation (28), $W_{\text {soc }}, W_{u}$, and $W_{\text {EGT }}$ are set according to Table 7. The simulation tests are carried out and the results are shown in Figure 18 and Table 8. As shown in Figure 18 and Table 8 , the results suggest that the error of the SOC from reference value 0.6 increases with the weight coefficient $W_{\text {soc }}$ decreasing, and large error of the SOC means bad efficiency and short life of the battery. On the other hand, the small weight coefficient $W_{\text {soc }}$ means the restriction on SOC is reduced, and more power from power battery is used to satisfy the requirements of driving power from driver, which decreases the power from turboshaft engine and contributes to the low EGT. On the contrary, the larger $W_{\mathrm{EGT}}$ has more benefits for low EGT rather than stable SOC.
In addition, when $W_{\mathrm{EGT}}$, the $W_{\text {soc }}$ is set as the same value in No. 5-6 in Table 7; the control performance is poor because of the large error of SOC from the reference value 0.6 . The results indicate that the $W_{\text {soc }}$ should be set larger than $W_{\text {EGT }}$ to maintain the SOC around the reference value. Although the larger $W_{\text {soc }}$ can lead to higher EGT, the increase in relative error of EGT is lower than the decrease in relative error of SOC. Therefore, large $W_{\text {soc }}$ and small $W_{\text {EGT }}$ should be selected for $\mathrm{P}^{2} \mathrm{MPC}$-based EMS.

Therefore, in order to determine the final weight coefficient, the $W_{\text {soc }}, W_{\text {EGT }}$, and $W_{u}$ are set shown in Table 9 , and the simulation results are shown in Figure 19 and Table 10. As shown in Figure 19 and Table 10, when the $W_{\text {soc }}=0.9$, $W_{\mathrm{EGT}}=0.05$, and $W_{u}=0.05$, the control performance is acceptable. Compared to the results of other configurations, there 


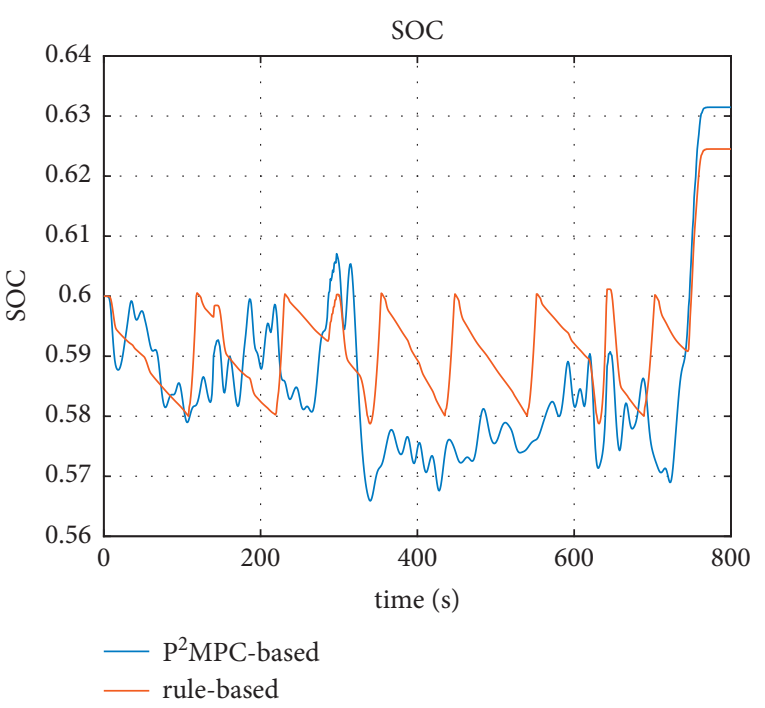

(a)

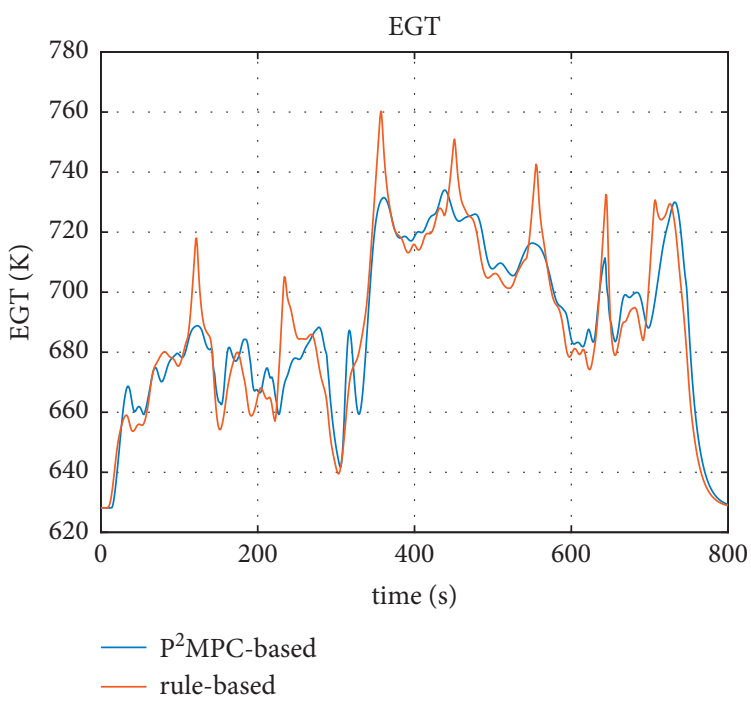

(b)

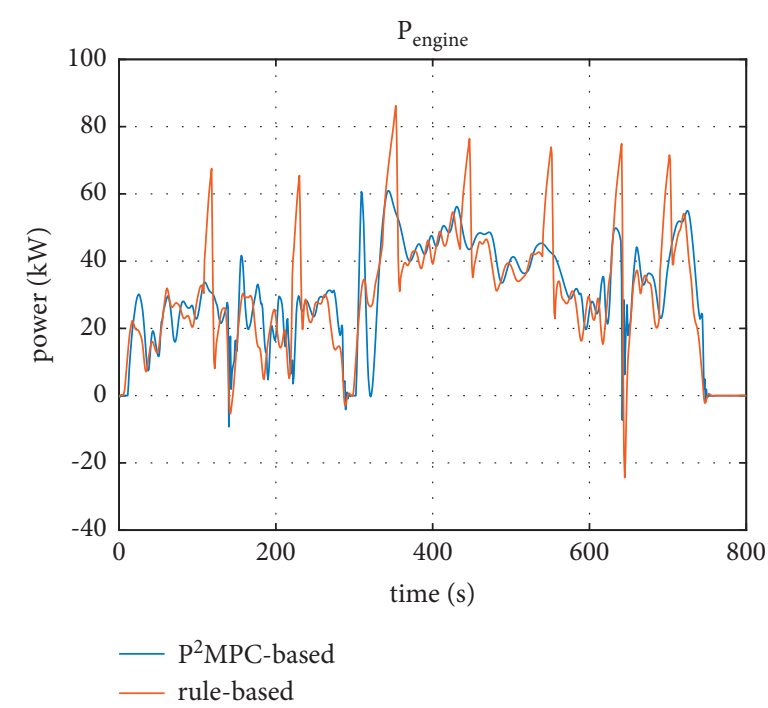

(c)

FIGURE 22: Simulation results comparison based on HWFET. (a) SOC of power battery. (b) EGT of turboshaft engine. (c) Output power of turboshaft engine.

are a few increases in the MARE and MERE of EGT; however, there are more decreases in the MARE and MERE of SOC. Therefore, based on the above comparison for the effect of different weight coefficients on all control performances, the weight coefficients of multiobject cost function of $\mathrm{P}^{2} \mathrm{MPC}$ are set as $W_{\text {soc }}=0.9, W_{\mathrm{EGT}}=0.05$, and $W_{u}=0.05$.

\subsubsection{Comparison between Rule-Based MPC and $P^{2} M P C$.} To better demonstrate the performance achieved by the proposed EMS, the power following rule-based EMS is introduced for comparisons. Besides UDDS, driving cycles of HWFET and LA92 are also used as the simulation references, as shown in Figure 20. In the rule-based EMS, the power of the engine-generator unit will follow the power demand from the signal of accelerator/brake pedal when the SOC belongs to the per-designed range. The engine-generator unit will offer the maximum output power or the minimum output power when the SOC is lower or higher than the limiting value and will follow the power demand from driver when SOC reaches the reference value.

The simulation results are shown in Figures 21-23 and Table 11. The maximum EGTs of turboshaft engine by the rulebased strategy are approximate 20 degrees Kelvin higher than that by $\mathrm{P}^{2} \mathrm{MPC}$ over the three driving cycles, and the FCs of engine power by rule-based EMS are larger than that by $\mathrm{P}^{2}$ MPC-based EMS. The results shown in Figures 21(c), 22(c), and 23(c) also show the turboshaft engine power by rule-based EMS change more sharply than that by $\mathrm{P}^{2}$ MPC-based EMS, which can lead to the unstable working state of turboshaft engine. The larger deviation of SOC in $\mathrm{P}^{2} \mathrm{MPC}$-based EMS is tolerable considering maintaining the turboshaft engine in stable working state. The results show $\mathrm{P}^{2} \mathrm{MPC}$-based EMS can offer the better control performance for vehicle with HPU. 


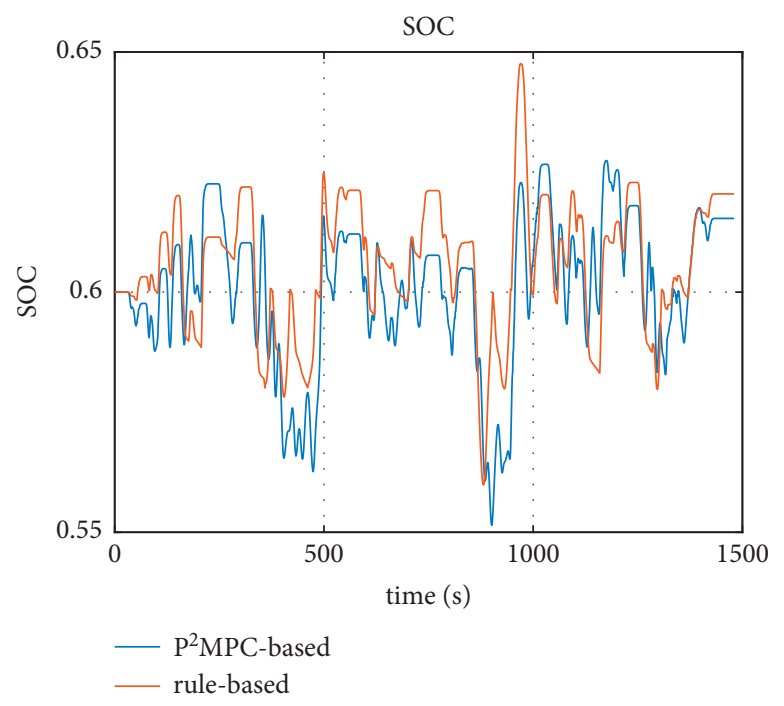

(a)

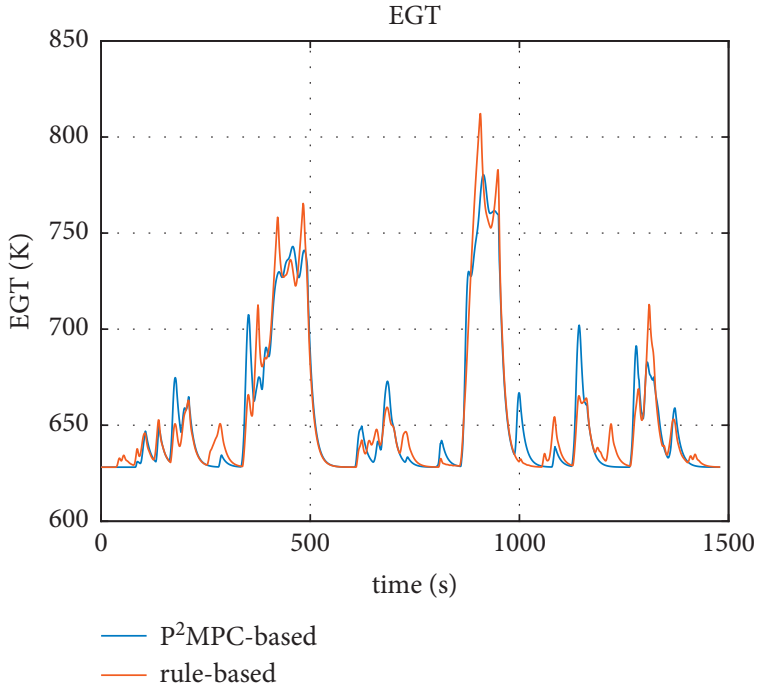

(b)

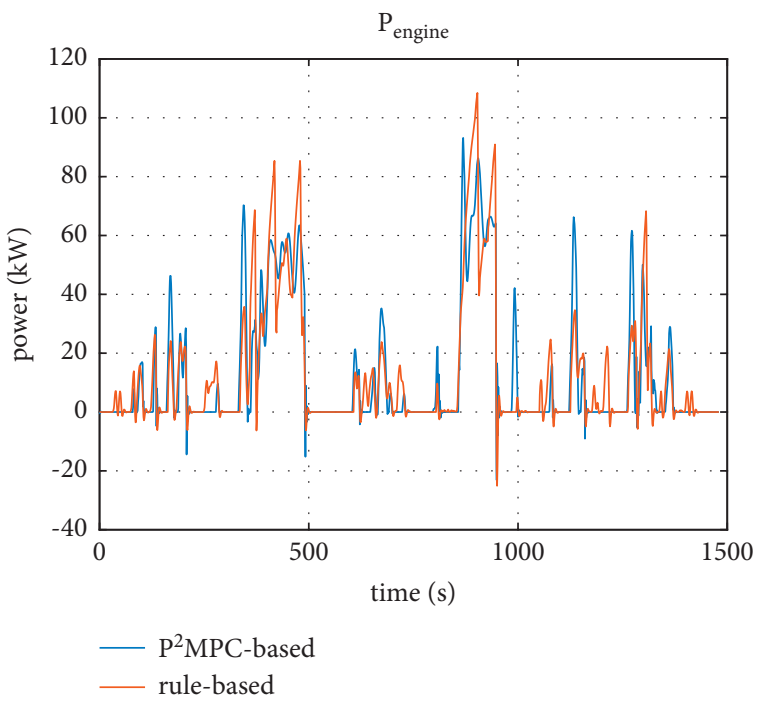

(c)

FIGURE 23: Simulation results comparison based on LA92. (a) SOC of power battery. (b) EGT of turboshaft engine. (c) Output power of turboshaft engine.

TABLE 11: Simulation results comparison.

\begin{tabular}{lcccccc}
\hline \multirow{2}{*}{ Driving cycle } & Method & MARE of SOC (\%) & $\begin{array}{c}\text { MERE of SOC } \\
(\%)\end{array}$ & $\begin{array}{c}\text { MARE of EGT } \\
(\%)\end{array}$ & MERE of EGT (\%) & FC of engine power \\
\hline \multirow{2}{*}{ UDDS } & Rule-based & 4.5158 & 1.7236 & 18.6499 & 1.9824 & 0.1395 \\
& $\mathrm{P}^{2}$ MPC-based & 11.4336 & 4.0963 & 16.0256 & 1.8883 & 0.0884 \\
\hline \multirow{2}{*}{ HWFET } & Rule-based & 4.0851 & 1.7339 & 21.0596 & 9.6665 & 0.0611 \\
& $\mathrm{P}^{2}$ MPC-based & 5.6837 & 3.0244 & 16.8776 & 9.6824 & 0.0514 \\
\hline \multirow{2}{*}{ LA92 } & Rule-based & 8.0931 & 2.0052 & 29.3241 & 4.0299 & 3.9536 \\
& $\mathrm{P}^{2}$ MPC-based & 7.9251 & 1.9754 & 24.2683 & & 0.1327 \\
\end{tabular}

\section{Conclusions}

In this paper, a new land and air vehicle powered by HPU with turboshaft engine is introduced, and in order to improve the efficiency and performance of the vehicle, the full model of the vehicle is established and the $\mathrm{P}^{2} \mathrm{MPC}$-based
EMS is proposed. First, a modeling method of turboshaft engine based on data-driven method is proposed, and the great accuracy of turboshaft engine model compared with experimental data is demonstrated by simulation results. To improve the accuracy of the predictive model of proposed $\mathrm{P}^{2} \mathrm{MPC}$, an integrated power demand predictor with state 
identifier is designed. The simulation results show that the predictive power demands in time steps which are closer to current time moment are more suitable for improving the control performance. Based the obtained full model of the vehicle and the power predictor, the prediction model of MPC including the SOC and EGT as state variables is established, where the first order inertial response of control variables is considered. The low EGT, small deviation of SOC from the reference, and small disturbance of control variables are concerned in the multiobjective optimization function of $\mathrm{P}^{2} \mathrm{MPC}$. The effects of the different weight coefficients on $\mathrm{P}^{2} \mathrm{MPC}$-based EMS are discussed, and a series of simulation results are demonstrated to determine the appropriate weight coefficients of optimization function. The simulation results between rule-based EMS and $\mathrm{P}^{2} \mathrm{MPC}-$ based EMS demonstrate the advantages of the proposed EMS in this paper.

\section{Data Availability}

Readers can obtain the datasets used in this work by contacting the corresponding author via e-mail: yuema@ bit.edu.cn.

\section{Conflicts of Interest}

The authors declare that they have no conflicts of interest regarding the publication of this paper.

\section{References}

[1] G. M. Bravo, N. Praliyev, and Á. Veress, "Performance analysis of hybrid electric and distributed propulsion system applied on a light aircraft," Energy, vol. 214, Article ID 118823, 2021.

[2] Z. Jiang and S. A. Raziei, "Hierarchical model predictive control for real-time energy-optimized operation of aerospace systems," in Proceedings of the 2019 AIAA/IEEE Electric Aircraft Technologies Symposium (EATS), Indianapolis, IN, USA, August 2019.

[3] Y. Xie, A. Savvarisal, A. Tsourdos, D. Zhang, and J. Gu, "Review of hybrid electric powered aircraft, its conceptual design and energy management methodologies," Chinese Journal of Aeronautics, vol. 34, no. 4, pp. 432-450, 2021.

[4] A. W. Wangai, D. Nguyen, and D. Rohacs, "Forecast of electric, hybrid-electric aircraft," International Symposiumon on electric Aviation and autonomous systems, vol. 44, pp. 26-29, 2019.

[5] J. T. Economou and S. Wang, "Design of a distributed hybrid electric propulsion system for a light aircraft based on genetic algorithm," in Proceedings of the AIAA propulsion and energy 2019, Indianapolis, IN, USA, August 2019.

[6] J. Rohacs and D. Rohacs, "Energy coefficients for comparison of aircraft supported by different propulsion systems," Energy, vol. 191, Article ID 116391, 2020.

[7] Y. Zhang, J. Chen, and Y. Yang, "Distributed power management with adaptive scheduling horizons for more electric aircraft," International Journal of Electrical Power \& Energy Systems, vol. 126, 2021.

[8] C. E. D. Riboldi, "Energy-optimal off-design power management for hybrid-electric aircraft," Aerospace Science and Technology, vol. 95, pp. 692-707, 2019.
[9] A. B. Petrochenkov, A. V. Romodin, D. Y. Leizgold, and A. S. Semenov, "Modeling power-supply systems with gasturbine units as energy sources," Russian Electrical Engineering, vol. 91, no. 11, pp. 673-680, 2020.

[10] T. Donateo, L. Cucciniello, L. Strafella, and A. Ficarella, "Control oriented modelling of a turboshaft engine for hybrid electric urban air-mobility," E3S Web of Conferences, vol. 197, Article ID 05003, 2020.

[11] B. Varga, L. Kavas, B. Békési, and K. Fehér, "Development of thermal mathematical model for turboshaft engines," Transport Means-Proceedings of the International Conference, vol. 2019, pp. 1323-1326, 2019.

[12] M. Pakmehr, N. Fitzgerald, E. Feron, J. Paduano, and A. Behbahani, "Physics-based dynamic modeling of a turboshaft engine driving a variable pitch propeller," Journal of Propulsion and Power, vol. 32, no. 3, pp. 646-658, 2016.

[13] S. Amin and M. Morteza, "Black box modeling of a turboshaft gas turbine engine fuel control unit based on neural NARX," Proceedings of the Institution of Mechanical Engineers-Part M: Journal of Engineering for the Maritime Environment, vol. 233, no. 3, pp. 949-956, 2019.

[14] H. Sheng, Q. Chen, J. Li et al., "Research on dynamic modeling and performance analysis of helicopter turboshaft engine's start-up process," Aerospace Science and Technology, vol. 106, Article ID 106097, 2020.

[15] J. H. Kim, T. W. Song, T. S. Kim, and S. T. Ro, "Model development and simulation of transient behavior of heavy duty gas turbines," Journal of Engineering for Gas Turbines \& Power, vol. 123, no. 3, pp. 589-594, 2001.

[16] Y.-D. Xing, J.-Q. Huang, F. Lu, and W.-R. Yao, "Research on simplified real-time model of turboshaft engine," Aeroengine, vol. 38, no. 2, 2012.

[17] F. Ji, X. Zhang, F. Du et al., "Experimental and numerical investigation on micro gas turbine as a range extender for electric vehicle," Applied Thermal Engineering, vol. 173, Article ID 115236, 2020.

[18] C. C. Chan-Chiao Lin, H. Huei Peng, J. W. Grizzle, and J. M. Jun-Mo Kang, "Power management strategy for a parallel hybrid electric truck," IEEE Transactions on Control Systems Technology, vol. 11, no. 6, pp. 839-849, 2003.

[19] B.-C. Chen, Y.-Y. Wu, and H.-C. Tsai, "Design and analysis of power management strategy for range extended electric vehicle using dynamic programming," Applied Energy, vol. 113, pp. 1764-1774, 2014.

[20] J. Peng, H. He, and R. Xiong, "Rule based energy management strategy for a series-parallel plug-in hybrid electric bus optimized by dynamic programming," Applied Energy, vol. 185, pp. 1633-1643, 2017.

[21] C. Xiang, F. Ding, W. Wang, and W. He, "Energy management of a dual-mode power-split hybrid electric vehicle based on velocity prediction and nonlinear model predictive control," Applied Energy, vol. 189, pp. 640-653, 2017.

[22] S. Zhang, R. Xiong, and F. Sun, "Model predictive control for power management in a plug-in hybrid electric vehicle with a hybrid energy storage system," Applied Energy, vol. 185, pp. 1654-1662, 2017.

[23] X. Wang, J. Chen, S. Quan, Y.-X. Wang, and H. He, "Hierarchical model predictive control via deep learning vehicle speed predictions for oxygen stoichiometry regulation of fuel cells," Applied Energy, vol. 276, Article ID 115460, 2020.

[24] H. Borhan, A. Vahidi, A. M. Phillips, M. L. Kuang, I. V. Kolmanovsky, and S. Di Cairano, "MPC-based energy management of a power-split hybrid electric vehicle," IEEE 
Transactions on Control Systems Technology, vol. 20, no. 3, pp. 593-603, 2012.

[25] K. T. Chau and Y. S. Wong, "Overview of power management in hybrid electric vehicles," Energy Conversion and Management, vol. 43, no. 15, pp. 1953-1968, 2002.

[26] Z. Song, H. Hofmann, J. Li, J. Hou, X. Han, and M. Ouyang, "Energy management strategies comparison for electric vehicles with hybrid energy storage system," Applied Energy, vol. 134, pp. 321-331, 2014.

[27] S. S. Keerthi and E. G. Gilbert, "Optimal infinite-horizon feedback laws for a general class of constrained discrete-time systems: stability and moving-horizon approximations," Journal of Optimization Theory and Applications, vol. 57, no. 2, pp. 265-293, 1988.

[28] H. Chen and F. Allgower, "A quasi-infinite horizon nonlinear model predictive control scheme with guaranteed Stability," Automatica, vol. 34, no. 10, pp. 1205-1217, 1998.

[29] L. Grüne and A. Rantzer, "On the infinite horizon performance of receding horizon controllers," IEEE Transactions on Automatic Control, vol. 53, no. 9, pp. 2100-2111, 2008.

[30] M. Yan, M. Li, H. He, and J. Peng, "Deep learning for vehicle speed prediction," Energy Procedia, vol. 152, pp. 618-623, 2018.

[31] J. Shin and M. Sunwoo, "Vehicle speed prediction using a Markov chain with speed constraints," IEEE Transactions on Intelligent Transportation Systems, vol. 20, no. 9, pp. 32013211, 2019.

[32] C. Sun, X. Hu, S. J. Moura, and F. Sun, "Comparison of velocity forecasting strategies for predictive control in HEVs," in Proceedings of the ASME 2014 Dynamic Systems and Control Conference, San Antonio, TX, USA, October 2014.

[33] Y. Huang, H. Wang, A. Khajepour, H. He, and J. Ji, "Model predictive control power management strategies for HEVs: a review," Journal of Power Sources, vol. 341, pp. 91-106, 2017. 